OPEN ACCESS

Edited by:

loan Opris,

University of Miami, USA

Reviewed by:

Yoshio Sakurai,

Doshisha University, Japan Brian R. Noga,

University of Miami, USA

${ }^{*}$ Correspondence:

Max O. Krucoff

max.krucoff@duke.edu

Specialty section:

This article was submitted to

Neuroprosthetics,

a section of the journal

Frontiers in Neuroscience

Received: 15 March 2016 Accepted: 06 December 2016 Published: 27 December 2016

Citation:

Krucoff MO, Rahimpour S,

Slutzky MW, Edgerton VR and Turner DA (2016) Enhancing Nervous

System Recovery through Neurobiologics, Neural Interface Training, and Neurorehabilitation.

Front. Neurosci. 10:584. doi: 10.3389/fnins.2016.00584

\section{Enhancing Nervous System Recovery through Neurobiologics, Neural Interface Training, and Neurorehabilitation}

\author{
Max O. Krucoff ${ }^{1 *}$, Shervin Rahimpour ${ }^{1}$, Marc W. Slutzky ${ }^{2,3}$, V. Reggie Edgerton ${ }^{4}$ and \\ Dennis A. Turner ${ }^{1,5,6}$ \\ ${ }^{1}$ Department of Neurosurgery, Duke University Medical Center, Durham, NC, USA, ${ }^{2}$ Department of Physiology, Feinberg \\ School of Medicine, Northwestern University, Chicago, IL, USA, ${ }^{3}$ Department of Neurology, Feinberg School of Medicine, \\ Northwestern University, Chicago, IL, USA, ${ }^{4}$ Department of Integrative Biology and Physiology, University of California, Los \\ Angeles, Los Angeles, CA, USA, ${ }^{5}$ Department of Neurobiology, Duke University Medical Center, Durham, NC, USA, \\ ${ }^{6}$ Research and Surgery Services, Durham Veterans Affairs Medical Center, Durham, NC, USA
}

After an initial period of recovery, human neurological injury has long been thought to be static. In order to improve quality of life for those suffering from stroke, spinal cord injury, or traumatic brain injury, researchers have been working to restore the nervous system and reduce neurological deficits through a number of mechanisms. For example, neurobiologists have been identifying and manipulating components of the intra- and extracellular milieu to alter the regenerative potential of neurons, neuro-engineers have been producing brain-machine and neural interfaces that circumvent lesions to restore functionality, and neurorehabilitation experts have been developing new ways to revitalize the nervous system even in chronic disease. While each of these areas holds promise, their individual paths to clinical relevance remain difficult. Nonetheless, these methods are now able to synergistically enhance recovery of native motor function to levels which were previously believed to be impossible. Furthermore, such recovery can even persist after training, and for the first time there is evidence of functional axonal regrowth and rewiring in the central nervous system of animal models. To attain this type of regeneration, rehabilitation paradigms that pair cortically-based intent with activation of affected circuits and positive neurofeedback appear to be required-a phenomenon which raises new and far reaching questions about the underlying relationship between conscious action and neural repair. For this reason, we argue that multi-modal therapy will be necessary to facilitate a truly robust recovery, and that the success of investigational microscopic techniques may depend on their integration into macroscopic frameworks that include task-based neurorehabilitation. We further identify critical components of future neural repair strategies and explore the most updated knowledge, progress, and challenges in the fields of cellular neuronal repair, neural interfacing, and neurorehabilitation, all with the goal of better understanding neurological injury and how to improve recovery.

Keywords: neurorehabilitation, neural stimulation, brain-machine interface (BMI), neuroplasticity, neural regeneration, neural interface, neural repair, spinal cord stimulation 


\section{INTRODUCTION}

Historically, for patients suffering from spinal cord injury (SCI), stroke, or traumatic brain injury (TBI), the prognosis for recovery has been poor, and patients with more complete and chronic injuries have shown the least potential for improvement (Jennett et al., 1976; Waters et al., 1992, 1996; Curt et al., 2008; Perel et al., 2008; Steyerberg et al., 2008; Lloyd-Jones et al., 2010). Researchers have been dedicated to improving the quality of life for these patients in several ways, e.g., (1) biological manipulation of the cellular milieu to encourage neuronal repair and regeneration (Magavi et al., 2000; Chen et al., 2002; Lee et al., 2004; Freund et al., 2006; Benowitz and Yin, 2007; Park et al., 2008; Maier et al., 2009; de Lima et al., 2012b; Dachir et al., 2014; Li et al., 2015; Omura et al., 2015), (2) creation of neural- or brainmachine interfaces designed to circumvent lesions and restore functionality (Wolpaw and McFarland, 1994; Kennedy and Bakay, 1998; Leuthardt et al., 2004; Monfils et al., 2004; Hochberg et al., 2006, 2012; Moritz et al., 2008; O'Doherty et al., 2009; Ethier et al., 2012; Collinger et al., 2013; Guggenmos et al., 2013; Ifft et al., 2013; Memberg et al., 2014; Zimmermann and Jackson, 2014; Grahn et al., 2015; Jarosiewicz et al., 2015; Soekadar et al., 2015; Bouton et al., 2016; Capogrosso et al., 2016; Donati et al., 2016; Hotson et al., 2016; Rajangam et al., 2016; Vansteensel et al., 2016), and (3) new rehabilitation techniques that include electrical stimulation and pharmacological enhancement of spinal circuitry to stimulate recovery (Carhart et al., 2004; Levy et al., 2008, 2016; Dy et al., 2010; Harkema et al., 2011, 2012; Dominici et al., 2012; van den Brand et al., 2012; Gad et al., 2013b, 2015; Angeli et al., 2014; Gharabaghi et al., 2014a,c; Wahl et al., 2014; Gerasimenko et al., 2015b). Unfortunately, the path to clinical relevance for these individual approaches remains long, and each field tends to operate largely in its own sphere of influence. Nonetheless, there is now emerging evidence that these methods may synergistically enhance recovery of native motor function that can persist even after the training period and is beyond what was previously thought possible (van den Brand et al., 2012; Guggenmos et al., 2013; Angeli et al., 2014; Wahl et al., 2014; Gad et al., 2015; García-Alías et al., 2015). Some animal models are even displaying functional axonal regrowth, sprouting, and rewiring never seen before in the central nervous system (CNS) of mammals (Bregman et al., 1995; Chen et al., 2002; Liebscher et al., 2005; Freund et al., 2006; Maier et al., 2009; van den Brand et al., 2012; Wahl et al., 2014; García-Alías et al., 2015). Throughout much of this work, evidence is emerging that combinatorial therapy across fields may actually be necessary to achieve significant and lasting neurological repair (Wahl et al., 2014; Gad et al., 2015). This paper explores the state of the art in each of these disciplines, identifies essential components of rehabilitation strategies, and argues why synthesizing approaches across specialties will be essential to realizing clinical applicability.

\section{THE BIOLOGY OF NEUROLOGICAL INJURY}

In order to understand how best to reverse or repair neurological injury, the mechanisms of cellular development and damage response must be appreciated. During maturation, young neurons of the CNS require activity (stimulated by purposeful actions like vision, walking, or hand function) and trophic factors to survive, grow, and prune (reviewed in Liu et al., 2011). Once mature, however, their axonal growth potential declines due to changes in intrinsic and extrinsic signaling factors, as well as established and stable synaptic fields. After lesioning, the distal portion of an axon undergoes Wallerian degeneration while the proximal portion seals the damaged membrane to form an end bulb (Schlaepfer and Bunge, 1973; Li and Raisman, 1995; Shetty and Turner, 1999; Hill et al., 2001; Fishman and Bittner, 2003). Eventually a growth cone is formed and injured corticospinal axons make an attempt to regrow; however, guidance cues are typically missing, and such efforts are therefore transient, abortive, and ultimately fail (Bernstein and Stelzner, 1983; Magavi et al., 2000; reviewed in Bulinski et al., 1998; Benowitz and Yin, 2007). This inability to regenerate is why injury to the CNS is so devastating and has been considered static once chronic.

After an insult, damaged CNS neurons continue a downward spiral of degeneration known as secondary injury. This includes an uncontrolled release of glutamate from presynaptic vesicles, loss of cell membrane potential, and damage to $\mathrm{N}$ methyl-D-aspartate (NMDA) and a-amino-3-hydroxy-5-methyl4-isoxazolepropionic acid (AMPA) receptors, all of which lead to overstimulation and increased neuronal death (Park et al., 1989; Goforth et al., 1999; Yurkewicz et al., 2005). Nitric oxide, triggered by the activation of NMDA receptors and intracellular calcium, interacts with stress-induced reactive oxygen species to cause DNA fragmentation, lipid peroxidation, and cellular death (reviewed in DeFina et al., 2009; Demirtas-Tatlidede et al., 2012; Villamar et al., 2012). Hemorrhage itself also exacerbates injury, as blood outside vessels releases excitatory amino acids, iron, and thrombin which induce further oxidative stress (Xi et al., 2006). The accumulation of excess intracellular zinc has too been shown to play a role in secondary injury by triggering neuronal death through intrinsic mechanisms such as $5^{\prime}$-adenosine monophosphate-activated protein kinase (AMPK) (Suh et al., 2000; Eom et al., 2016). These mechanisms of primary and secondary neurologic injury are summarized in Table 1.

Upon cell dissolution and fragmentation, inflammation is triggered, resulting in the clean-up of dead cells, disconnection of nonfunctional synapses, release of pro- and anti-inflammatory cytokines, and disruption of the blood-brain-barrier (BBB) (reviewed in Greve and Zink, 2009). This drives astrocytes and endothelial cells to produce more inflammatory mediators and impairs the brain's ability to manage its own perfusion status [i.e., autoregulate cerebral blood flow (CBF)]. During the first hours after injury, decreased perfusion and cerebral ischemia is seen, followed by a second phase of increased perfusion with increased intracranial pressure (ICP), and a final phase of vasospasm and again reduced perfusion (reviewed in Villamar et al., 2012). Until about 10-14 days after injury, inflammation helps to prime the extracellular milieu for subsequent axonal entry and re-innervation (Shetty and Turner, 1995). Resolution of acute inflammation is mediated by apoptosis of the inflammatory cells and endogenous antiinflammatory mediators (reviewed in Villamar et al., 2012). 
A brief timeline of the injury environment is provided in Figure 1.

As a result of these inflammatory processes, cerebral edema tends to emerge during the secondary injury and can be either vasogenic or cytotoxic (Marmarou et al., 2006). Vasogenic edema results from vasodilation, increased permeability of the $\mathrm{BBB}$, and accumulation of molecules in the interstitial fluid. Cytotoxic edema is due to metabolic derangements within cells that lead to changes in osmolality, swelling, and death, often from inadequate metabolism or too severe ionic load for the membrane pumps to handle (reviewed in Greve and Zink, 2009; Zink et al., 2010; Villamar et al., 2012).

While the spinal cord shares certain mechanisms of injury with the brain, its injury patterns also have some important differences. For example, the most frequent primary cause of SCI is traumatic acute compression, and usually at least some subpial neurological tissue is preserved (Wolman, 1965; Tator and Edmonds, 1979; reviewed in Tator, 1995). Mechanical trauma preferentially affects the central gray matter of the cord, likely due to its vascularity and softer consistency, and can cause necrosis, edema, hemorrhage, and vasospasm (Wolman, 1965; reviewed in Tator, 1995). A cascade of secondary

TABLE 1 | Mechanisms of neurological injury.

\begin{tabular}{ll}
\hline Primary injury & Secondary injury \\
\hline Blunt trauma & Excitotoxicity (NMDA/AMPA-glutamate) \\
Penetrating trauma & Reactive O2 species (cytochrome c-caspase, GSH) \\
Necrosis/apoptosis & Nitric oxide (DNA fragmentation, lipid peroxidation \\
Degenerative disease & Zinc toxicity (PKC, NADPH, nNOS, PARP, AMPK) \\
Ischemia/stroke & Inflammation (BBB and CBF disruption, vasospasm) \\
Hemorrhage & Hemorrhage products (amino acids, iron, thrombin) \\
Infection & Cerebral edema (vasogenic, cytotoxic) \\
& Stroke sequelae (elevated ICP, edema, vasospasm) \\
\hline
\end{tabular}

NMDA, N-methyl-D-aspartate; AMPA, $\alpha$-amino-3-hydroxy-5-methyl-4-isoxazolepropionic acid; GSH, glutathione; DNA, deoxyribonucleic acid; PKC, protein kinase C; NADPH, nicotinamide adenine dinucleotide phosphate-oxidase; nNOS, neuronal nitric oxide synthase; PARP, poly adenosine diphosphate (ADP) ribose polymerase; AMPK, adenosine monophosphate (AMP)-activated protein kinase; BBB, blood brain barrier; $C B F$, cerebral blood flow; ICP, intracranial pressure. pathophysiology similar to that seen in the brain follows, including ischemia, apoptosis, necrosis, fluid and electrolyte disturbances, excitotoxicity, production of free radicals, lipid peroxidation, and an inflammatory response. These processes result in further neurological damage, swelling, and ischemia. Ultimately, a large fluid-filled cavity or cyst forms in the center of the injured cord surrounded by a subpial rim of preserved axons, many of which become demyelinated. Hypertrophic astrocytes and macrophages secrete extracellular matrix and inhibitory molecules that form a glial scar-a physical and chemical barrier to neural regeneration (reviewed in Tator and Fehlings, 1991; Tator, 1995; Mothe and Tator, 2012).

Although intuitively attractive, attempts to mitigate secondary injury and improve recovery with pharmaceutical therapies have been well studied with modest results at best (DeFina et al., 2010; reviewed in Breceda and Dromerick, 2013; Krieger, 2013). In the acute phase of brain injury, suppression of glutamatergic activity appears to be beneficial in minimizing neurological damage and disability (Liu et al., 2013). In the subacute phase, modulation of GABAergic inhibition can minimize the functional impact of an injury (reviewed in Demirtas-Tatlidede et al., 2012). Other drugs that have been used to enhance motor recovery after TBI and/or stroke include naltrexone, bromocriptine, fluoxetine, venlafaxine, levo/carbidopa, donepezil, modafinil, rivastigmine, desipramine, zolpidem, amantadine, methylphenidate, dextroamphetamine, and rasagiline (reviewed in DeFina et al., 2010; Breceda and Dromerick, 2013; Krieger, 2013). Most of these drugs are aimed at normalizing the electrochemical balance of the injured brain to optimize its ability to heal and minimize secondary injury. Dopaminergic medications have also been shown to promote gamma band activity during attention through D4 receptor activation (Kuznetsova and Deth, 2008). Nicotinamide too may help reverse severe oxidation, likely through mitochondrial mechanisms (Shetty et al., 2014), and some authors have suggested that blockade of AMPK in acute brain injury may protect against zinc neurotoxicity (Eom et al., 2016).

Selective serotonin reuptake inhibitors (SSRIs) like fluoxetine play a role in treating depressive symptoms that often accompany neurological disease (thought to be associated

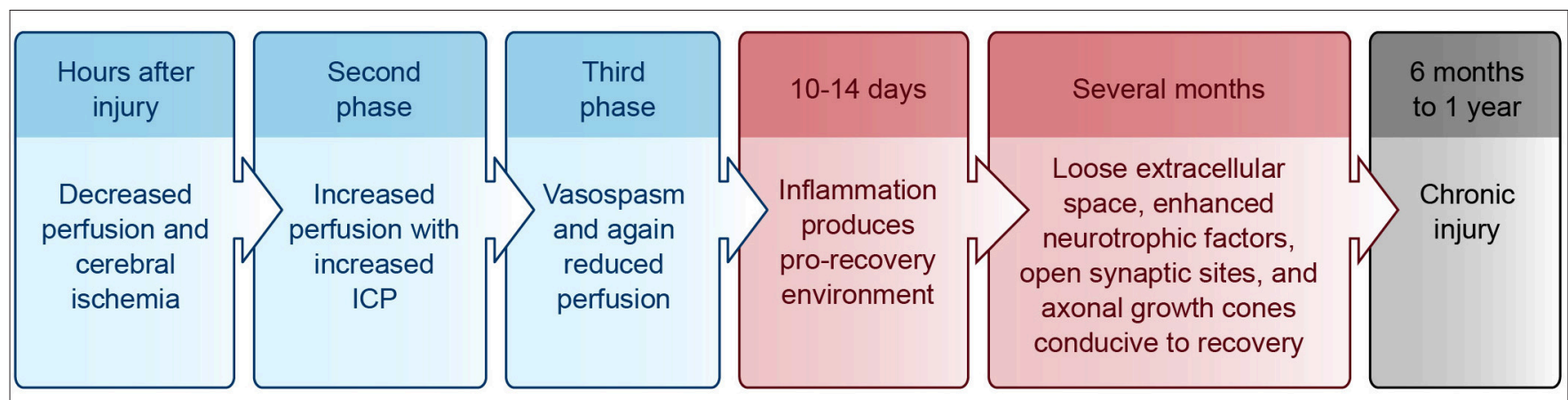

FIGURE 1 | Injury environment timeline. Blue, acute phase; Red, subacute phase; Black, chronic phase. ICP, intracranial pressure. 
with disruption of corticostriatal and thalamocortical loops) (Terroni et al., 2011). Treating depression is crucial to recovery but is often overlooked, as the symptoms of depression and learned helplessness can be found in up to $30 \%$ of early stroke patients (Hackett et al., 2014). Vitamins and antioxidants such as essential amino acids, minerals, cofactors, and "immunonutrition" [omega 6 and omega 3 fatty acids, arginine, glutamine, ribonucleic acids (RNAs), mycelia extracts] have all demonstrated modest but generally benign results (DeFina et al., 2010). Additionally, recent evidence suggests that prophylactic anticonvulsants like phenytoin in stroke/TBI are associated with worse functional outcomes, possibly due to reduced axonal/growth cone bursting from sodium channel suppression which may inhibit rewiring (Bhullar et al., 2014). The optimal timing of seizure prophylaxis after brain injury, if beneficial at all, remains open to debate (Thompson et al., 2015).

\section{MOLECULAR MECHANISMS OF NEURAL REPAIR}

In addition to the injury mechanisms and glial scar described above, there are many biological mediators that alter the ability of the CNS to repair itself after injury. Intrinsic factors including transcription factors (c-Jun, Atf3, Klf family, Stat3, Sox11, and Smad1) and regeneration-associated genes (Gap43, Cap23, Arg1, Sprr1a, Hspb1, MARCKS, stathmin family, SCG10 L1, P21/waf1, and tubulins) have been shown to alter restoration potential (Grenningloh et al., 2004; Carmichael et al., 2005; reviewed in Sun and He, 2010; Tedeschi, 2011). Phosphatase and tensin homolog (PTEN), a tumor suppressor, seems to play an important role as eliminating its gene has been shown to both prevent apoptosis and induce axon extension in injured retinal ganglion cells (RGCs) (Park et al., 2008; de Lima et al., 2012b). Deletion of Socs3, a suppressor of signaling through the Jak-STAT pathway, also promotes regeneration by enhancing the efficacy of ciliary neurotrophic factor (CNTF) (Smith et al., 2009). If the mechanistic target of rapamycin (mTOR) is inhibited, the regenerative effect of PTEN deficiency is eradicated, suggesting that axon regeneration induced by PTEN deletion is dependent on the mTOR pathway (Park et al., 2008). The proto-oncogene bcl-2 (and expression of its anti-apoptotic protein) also plays a key role in preventing cell death after injury, enabling axonal regrowth in RGCs with the presence of trophic factors and physiologic electrical activity (Chen et al., 1997; Goldberg et al., 2002).

Extrinsic factors that prevent axonal regeneration include inhibitory proteins associated with myelin [e.g., NogoA, myelin-associated glycoprotein (MAG), and oligodendrocyte-myelin glycoprotein (OMgp)], proteoglycans in the perineuronal net and glial scar [e.g., chondroitin sulfate proteoglycans (CSPGs) like aggrecan, versican, brevican, neurocan, NG2, and phosphacan], and molecules that repel axon growth during development which continue to be expressed in the mature CNS (e.g., semaphorins, ephrins, slits, netrins, robos, and Wnts) (reviewed in Benowitz and Yin, 2007; Benowitz and Carmichael, 2010; de Lima et al., 2012a; Omura et al., 2015). A summary of intrinsic and extrinsic factors affecting neural growth and inhibition is provided in Figure 2.

\begin{tabular}{|c|}
\hline Intracellular \\
\hline $\begin{array}{c}\text { Regeneration-associated genes } \\
\text { (GAP43, GDF10, CAP23, ARG1, SPRR1, } \\
\text { HSPB1, tubulins, L1, MARCKS, SCG10, } \\
\text { stathmin family, and p21/waf1) }\end{array}$ \\
\hline $\begin{array}{c}\text { Transcription factors } \\
\text { (c-Jun, Atf3, KIf family, } \\
\text { Stat3, Sox11, and Smad1) }\end{array}$ \\
\hline $\begin{array}{c}\text { Inflammation + PTEN deletion } \\
\text { and elevation of cAMP }\end{array}$ \\
\hline Deletion of Socs3 \\
\hline Anti-apoptotic proteins \\
(Bcl-2) \\
\hline Deletion of all NgR isoforms \\
\hline Inosine
\end{tabular}

\begin{tabular}{|c|}
\hline Extracellular \\
\hline $\begin{array}{c}\text { Myelin inhibitory proteins } \\
\text { (Nogo-A, MAG, OMgp) }\end{array}$ \\
\hline $\begin{array}{c}\text { Glial scar } \\
\text { (CSPGs, aggrecan, versican, brevican, } \\
\text { neurocan, NG2, phosphacan) }\end{array}$ \\
\hline $\begin{array}{c}\text { Repellant molecules } \\
\text { (semaphorins, ephrins, slits, } \\
\text { netrins, robos, and Wnts) }\end{array}$ \\
\hline $\begin{array}{c}\text { Overexpression of OPN + IGF1 + CNTF } \\
\text { (GDF10, CNTF) }\end{array}$ \\
\hline Oncomodulin + inflammation \\
\hline
\end{tabular}

FIGURE 2 | Intra- and extracellular mechanisms of neuronal growth and inhibition. Blue, associated with neuronal growth; Red, associated with neuronal inhibition; Black, modulates both neuronal growth and inhibition. PTEN, phosphatase and tensin homolog; cAMP, cyclic adenosine monophosphate; GAP43, growth associated protein 43; GDF10, growth differentiation factor 10; CAP23, cytoskeleton-associated protein; ARG1, arginase 1; SPRR1, small proline-rich protein 1; HSPB1, heat shock protein family B (small) member 1; MARCKS, myristoylated alanine-rich C-kinase substrate; SCG10, superior cervical ganglion 10; NgR, nogo receptor; CSPG, chondroitin sulfate proteoglycans; NG2, neural/glial antigen 2; MAG, myelin-associated glycoprotein; OMgp, oligodendrocyte-myelin glycoprotein; CNTF, ciliary neurotrophic factor; OPN, osteopontin; IGF1, insulin-like growth factor 1. 
Despite identification of these molecules as being important, removal or blockage of extracellular inhibitory factors alone so far has failed to achieve extensive axonal regeneration with a few exceptions (Alilain et al., 2011; reviewed in Benowitz and Yin, 2007; Benowitz and Carmichael, 2010; Liu et al., 2011). Interestingly, a strain of dorsal root ganglion neurons grown from CAST/Ei knockout mice are less inhibited by the same extrinsic cues listed above (Omura et al., 2015). Large regenerative responses have been noted in these cells, and activin seems to play an important role. Also, deletion of receptors that bind to myelin-associated inhibitory molecules (MAIs), or Nogo (NgR) receptors, has been shown to increase regeneration potential in neurons (Dickendesher et al., 2012). This is why anti-Nogo immunotherapies are currently of great interest as potential treatments for neurological injury (Lee et al., 2004; Freund et al., 2006; Maier et al., 2009; Wahl et al., 2014). In fact, immunotherapies aimed at blocking inhibitory factors like NogoA have successfully demonstrated increased sprouting associated with functional recovery in both rat (Bregman et al., 1995; Liebscher et al., 2005; Maier et al., 2009) and primate (Freund et al., 2006) models of SCI. In 2014, Wahl et al. published near full recovery of skilled forelimb function in rats with large strokes after intrathecal injection of an antiNogoA antibody followed by intensive task-specific training (Wahl et al., 2014). Injection of the NogoA neutralizing agent was shown to promote growth of corticospinal fibers from the intact forebrain motor cortex across the midline of the cervical spinal cord to the hemicord that had lost its input from the motor cortex. This new fiber sprouting was then stabilized by a goal-directed physical therapy regimen. Interestingly, sequential application of drug then training was necessary to show benefit. When immunotherapy and forced-use training were combined simultaneously, functional outcome was poorer compared to no treatment at all or each treatment individually, likely due to abundant but aberrant fiber branching (also seen in Maier et al., 2009). This example outlines the important distinction between regrowth with synapse formation and the restoration of function.

Another example of this principle was demonstrated by Bei et al. in showing that PTEN/SOCS3 co-deletion or overexpression of osteopontin (OPN)/insulin-like growth factor 1 (IGF1)/CNTF could induce regrowth of adult mouse retinal axons to synapse in the superior colliculus, but this connection did not restore visual function on its own (Bei et al., 2016). In fact, these regenerated axons failed to conduct action potentials (APs) due to lack of myelination, and administration of voltagegated potassium channel blockers was required to enable proper conduction and improve visual acuity.

Despite the litany of inhibitory mechanisms examined above, there are also signals released in the injured brain that are known to promote axonal growth after injury. For example, growth and differentiation factor 10 (GDF10) is induced in stroke and works through transforming growth factor beta receptors I and II (TGFßRI and TGF $\beta$ RII) to promote axonal outgrowth (Li et al., 2015). Growth associated protein 43 (GAP43), a neuronal growth cone marker, is also induced in peri-infarct cortex after stroke (Stroemer et al., 1995; Schaechter et al., 2006). The purine nucleoside inosine works through a direct intracellular mechanism to induce expression of genes associated with axonal growth (e.g., GAP43, L1, and $\alpha-1$ tubulin) and has been shown to induce axonal reorganization and improve behavioral outcomes after spinal cord injury and stroke (Zai et al., 2009, 2011; Kim et al., 2013), as well as restore levels of GAP43 in the hippocampus in rats after stroke (Chen et al., 2002; de Lima et al., 2012b; Dachir et al., 2014).

The role of inflammation in axonal regeneration is somewhat controversial. Some components of inflammation cause tissue damage and neuronal death (see The Biology of Neurological Injury section), while others promote cell survival, axon sprouting, and regeneration (Shetty and Turner, 1995; Yin et al., 2003; de Lima et al., 2012a; Kurimoto et al., 2013; Baldwin et al., 2015; reviewed in Benowitz and Popovich, 2011). Both oncomodulin, a macrophage-derived growth factor for RGCs, and injury-induced cytokine release appear to play a role in inflammation-induced axonal regeneration (Yin et al., 2006, 2009; Kurimoto et al., 2013). Traditional anti-inflammatory therapies (e.g., NSAIDs such as ibuprofen) may suppress beneficial as well as deleterious aspects of the immune response, and they can stimulate axonal regeneration via direct effects on neurons (reviewed in Benowitz and Yin, 2008; Benowitz and Carmichael, 2010; Benowitz and Popovich, 2011). When combined with PTEN deletion and elevation of cyclic adenosine monophosphate (cAMP), intraocular inflammation will enable some retinal ganglion cells to regenerate injured axons from the eye to the brain and restore simple visual responses (de Lima et al., 2012b).

\section{THE PHYSIOLOGY OF RECOVERY FROM NEUROLOGICAL INJURY}

In addition to the molecular and intracellular mechanisms mentioned above, proper function of the neuraxis also relies on the appropriate establishment and maintenance of intercellular mechanisms. Although the CNS does not fully self-repair after injury, neurogenesis does occur naturally in the healthy adult brain. This process happens primarily in the subgranular and subventricular zones (SGZ and SVZ, respectively), and it helps support learning, memory, and olfaction (Doetsch et al., 1999; Laywell et al., 2000; Seri et al., 2001; reviewed in Alvarez-Buylla and Lim, 2004; Ohab and Carmichael, 2008). These areas contain niches of progenitor, glial, and endothelial cells that can selfrenew or differentiate into a glial or neuronal lineage. The SGZ supplies the dentate gyrus of the hippocampus and the SVZ gives cells to the olfactory bulb to integrate into local circuitry and support function. There is evidence that damage from stroke stimulates cell proliferation within these zones, and immature neurons are recruited into damaged areas of the striatum and cortex. This process starts at 2 weeks and lasts up to several months after injury (Macas et al., 2006; Thored et al., 2006). Initially, tens of thousands of immature neurons can migrate to damaged areas. However, few mature and survive long-term (Zhang et al., 2001; Arvidsson et al., 2002). While the generation and migration of new neurons to damaged areas is associated with functional recovery, it is possible that behavioral recovery is 
achieved through mechanisms other than neuronal replacement, e.g., growth factor production in local tissue (reviewed in Ohab and Carmichael, 2008).

Other more prominent mechanisms of restoration of function include reduction in edema, resolution of diaschisis (loss of function in connected areas of the brain due to inactivity, loss of blood flow, and decreased metabolism), and optimization of remaining motor areas (Nudo and Milliken, 1996; reviewed in Feeney and Baron, 1986). Neural plasticity and reorganization occur through the uncovering of previously latent synapses, collateral sprouting of synapses from nearby intact neurons, strengthening or weakening of existing synapses [e.g., through long-term potentiation (LTP) or long-term depression (LTD)], and changes in concentrations of neurotransmitters, ions, gap junctions, and glial cells (reviewed in DeFina et al., 2009; Demirtas-Tatlidede et al., 2012; Villamar et al., 2012; Nahmani and Turrigiano, 2014). These mechanisms are outlined in Table 2. While neural plasticity contributes significantly to functional recovery, it should be noted that not all types are beneficial. For example, maladaptive plasticity and inappropriate axonal sprouting can lead to spasticity, pathological pain, schizophrenia, and seizures (Dimitrijevi and Nathan, 1967; Flor et al., 1995; Teyler et al., 2001; Quartarone et al., 2008; Thickbroom and Mastaglia, 2009; Kuner, 2010; Hasan et al., 2011).

Though long-range axonal sprouting was once thought to be non-existent in adult mammals, evidence now supports this possibility in animal models (Chen et al., 2002; Liebscher et al., 2005; Freund et al., 2006; Maier et al., 2009; van den Brand et al., 2012; Wahl et al., 2014). Context-dependent cortical activity and functional growth cones paired with positive feedback seems to be critical for this type of axonal sprouting to generate robust and lasting functional improvement (van den Brand et al., 2012; Wahl et al., 2014). Even without long-range axonal sprouting, some level of functional improvement can occur via other mechanisms of neural plasticity. For example, after stroke, both hemispheres are known to assist with recovery depending on the size of the injury (Dancause, 2005; reviewed in Dancause and Nudo, 2011; Kantak et al., 2012). Following a small stroke within the primary motor cortex (M1) or the corticospinal tract, both ipsilesional dorsal and ventral premotor cortices (PMCs) can reorganize themselves. However, when a

TABLE 2 | Mechanisms of neurological recovery.

Reduction in edema

Resolution of diaschisis

Optimization of remaining motor areas

Reorganization

Collateral sprouting from local intact neurons

Changes in concentrations of neurotransmitters, ions, gap junctions, and glial cells

*Theoretical, or proven in animal models only. SGZ, subgranular zone; SVZ, subventricular zone. lesion involves a larger portion of M1 and the dorsal PMC, the contralesional PMC appears to be critical for recoveryrelated reorganization (reviewed in Dancause and Nudo, 2011; Kantak et al., 2012). Initiation of post-infarct axonal sprouting from the intact cortical hemisphere to peri-infarct cortex and the contralateral dorsal striatum is signaled by synchronous neuronal activity (Carmichael and Chesselet, 2002). In chronic stroke patients, activity in ipsilesional primary motor and medialpremotor cortices has been shown to be associated with good motor recovery, whereas increased cerebellar vermis activity signals poor recovery (Favre et al., 2014).

For up to several months after the initial injury, the neural environment remains conducive to recovery due to its relatively loose extracellular space, enhanced neurotrophic factors, open synaptic sites, and probing axonal growth cones (Napieralski et al., 1996; Carmichael et al., 2005; reviewed in Nudo, 2013). After 6 months to 1 year, injuries have been classically considered chronic with little opportunity for further gain, although this doctrine is beginning to change (Figure 1) (reviewed in Langhorne et al., 2011; Teasell et al., 2014).

\section{THE NEUROPHYSIOLOGY UNDERLYING BRAIN-MACHINE AND NEURAL INTERFACE TRAINING}

Neural- or brain-machine interfaces are electrode-computer constructs that extract and decode information from the nervous system to generate functional outputs. These have been developed to bypass motor lesions (assistive BMIs) (Wolpaw and McFarland, 1994; Kennedy and Bakay, 1998; Leuthardt et al., 2004; Moritz et al., 2008; Ethier et al., 2012; Collinger et al., 2013; Memberg et al., 2014; Jarosiewicz et al., 2015; Bouton et al., 2016; Capogrosso et al., 2016; Hotson et al., 2016; Rajangam et al., 2016; Vansteensel et al., 2016; reviewed in Lobel and Lee, 2014) and, more recently, to facilitate neural plasticity and motor learning to enhance recovery after injury (rehabilitative BMIs) (Carhart et al., 2004; Buch et al., 2008; van den Brand et al., 2012; Ang et al., 2013; Ramos-Murguialday et al., 2013; Wahl et al., 2014; Gharabaghi et al., 2014a,b,c; Gerasimenko et al., 2015b; Donati et al., 2016; reviewed in Ethier et al., 2015; Jackson and Zimmermann, 2012).

Interfaces generally contain at least four components: (1) a method of extracting signals from the nervous system, (2) a way to decode the signals to predict user intent, (3) an output to affect the subject's environment, and (4) a feedback system to help the user refine the output (e.g., visual or other sensory modality). Means of extracting nervous system signals range from invasive [intracortical microelectrodes (APs, or spikes) and larger scale sub- or epidural electrodes (electrocorticography, ECoG)] to non-invasive [electroencephalography (EEG) or electromyography (EMG)]. Targeted outputs have included cursors on a screen (Wolpaw and McFarland, 1994; Kennedy and Bakay, 1998; Leuthardt et al., 2004; McFarland et al., 2010), virtual typing (Jarosiewicz et al., 2015), robotic or prosthetic arms (Collinger et al., 2013; Hotson et al., 2016), wheelchairs (Rajangam et al., 2016), exoskeletons (Donati et al., 2016), 
the spinal cord (Zimmermann and Jackson, 2014; Capogrosso et al., 2016), and a patient's own extremities (Ethier et al., 2012; Memberg et al., 2014; King et al., 2015; Bouton et al., 2016; Vidaurre et al., 2016).

While initially developed due to the belief that the human nervous system could not self-regenerate (as examined in the previous sections), BMIs have also led to exciting and innovative ways to understand and interact with the nervous system. Current understanding of brain function recognizes an intricate arrangement of interconnected units and circuits that contribute to a larger performing network, as opposed to older models which viewed the brain as a collection of independent anatomical modules with discrete functions (Breakspear and Stam, 2005; Serences and Yantis, 2006; reviewed in Meunier et al., 2010). It has been shown that functionally coupled remote brain locations display near synchronous discharges that represent emergent properties of their assimilated networks (Breakspear and Stam, 2005; Womelsdorf et al., 2007; Stevenson et al., 2012; Menzer et al., 2014). This dispersion of information likely explains why motor information can be found widely distributed throughout the cortex, and how random samples of neurons can provide enough information to reconstruct certain movements in great detail (Carmena et al., 2003; Fitzsimmons et al., 2009; reviewed in Nicolelis and Lebedev, 2009). However, it has also been shown that no matter how well tuned a single neuron is to a behavioral task, that an individual cell only contains limited information and can vary greatly over a short period of time (Wessberg et al., 2000; Carmena et al., 2003). Interestingly, once an ensemble of neurons reaches a certain size, its collective predictive ability plateaus, suggesting that there is redundancy in the neuronal network, and that there are a critical number of neurons required to decode motor intention (Carmena et al., 2003; Vargas-Irwin et al., 2010; reviewed in Donoghue, 2008; Nicolelis and Lebedev, 2009). Collectively, these concepts have led to population algorithms, or decoders that exploit the idea that individual neurons encode multiple parameters with different weights and may vary from trial to trial; however, useful information is maintained among a population instead of individual neurons. The advantage of population decoding systems is that they work even when individual neurons poorly encode motor behavior. These algorithms, in addition to advances in technology that have enabled largescale recordings of single-neuron activity patterns, have led to the success of many BMIs described in the following section.

The true language of the motor cortex, or how the motor cortex encodes its output signals, is a subject of debate (VargasIrwin et al., 2010; Cherian et al., 2011). Coordinated actions of the limbs may engage widespread cortical areas, and M1 is known as the site where motor plans tend to merge before diverging to multiple muscle groups (Vargas-Irwin et al., 2010). While M1 clearly contains kinematic information (joint position and trajectory) sufficient for accurate predictions (Vargas-Irwin et al., 2010), there is evidence that it may more directly encode kinetic (force) variables (Morrow et al., 2007; Cherian et al., 2011; Flint et al., 2014). This would suggest that BMIs built to encode force and/or EMG signals may be more robust across different positional dynamics than trajectory-based BMIs.
For gait decoding, there is evidence that motor cortex BMIs may perform better when estimating gait phases or locomotor behaviors as opposed to continuous kinematic variables of leg movement (Rigosa et al., 2015). Interestingly, bimanual arm control appears to have its own representation in the cortex and does not seem to be described simply by a superposition of unilateral movements (Ifft et al., 2013).

As attempts for more dexterous and intuitive control of neural interfaces are pursued, the question of how many independent control signals can be extracted from a neural ensemble arises. The human arm has 7 degrees of freedom (DOF), and the hand has more than 20 (Stockwell, 1981; Jones, 1997). As it turns out, natural grasp postures and reaching-to-grasp movements exist in a much smaller subspace than physically possible movements (Ingram et al., 2008). Dimensionality reduction techniques like principal component analysis (PCA) show that a large proportion of the variance of natural grasping behaviors can be represented by two to three principal components. This provides a strategy for neural interfaces to recapitulate potentially more complex appearing movements while extracting fewer degrees of freedom (reviewed in Hatsopoulos and Donoghue, 2009). An example of such a technique is shown in Figure 3 (Krucoff and Slutzky, 2011).

In recent years, neural interfaces have been developed to modulate neural plasticity and enhance recovery (rehabilitative BMIs) in addition to bypassing lesions (assistive BMIs). The transition from assistive to rehabilitative BMIs has come with the realization that patients with a chronic neurologic injury may not be at a static level of functioning as previously thought, and that underlying networks even in chronic injury can be modified over time (Guggenmos et al., 2013; reviewed in Jackson and Zimmermann, 2012). A diagram showing the conceptual difference in approach to assistive vs. rehabilitative BMIs is provided in Figure 4. Rehabilitative BMIs pair goal-oriented tasks with expected outcomes and work to activate lesioned circuits to create plasticity for long-lasting improvements. This approach takes advantage of a principle called spike timing dependent plasticity (STDP), or Hebbian plasticity (often expressed as, "neurons that fire together wire together") (Hebb, 1949; Cooper, 2005). This is the idea that synaptic strength is redistributed to favor functionally relevant pathways that are coincidently active, inferring that both the sign and magnitude of synaptic modification are determined by the precise timing of APs (Rebesco and Miller, 2011). The best known example of Hebbian plasticity is perhaps LTP and LTD in memory circuits. For modeling of complex, larger scale circuits, the Bienenstock-Cooper-Munro (BCM) model maybe more representative of behavior. This theory incorporates both presynaptic and postsynaptic firing rates (Bienenstock et al., 1982; reviewed in Cooper and Bear, 2012) and applies a sliding threshold for LTP/LTD based on post-synaptic activity as the metric for stabilization.

A related concept employed in some rehabilitative BMIs is paired associative stimulation (PAS), or the act of pairing stimulation sites to promote plasticity (Stefan et al., 2000; Carson and Kennedy, 2013). An example of a commonly used central stimulation strategy is transcranial magnetic stimulation (TMS). TMS involves applying rapidly changing magnetic fields to the 
A

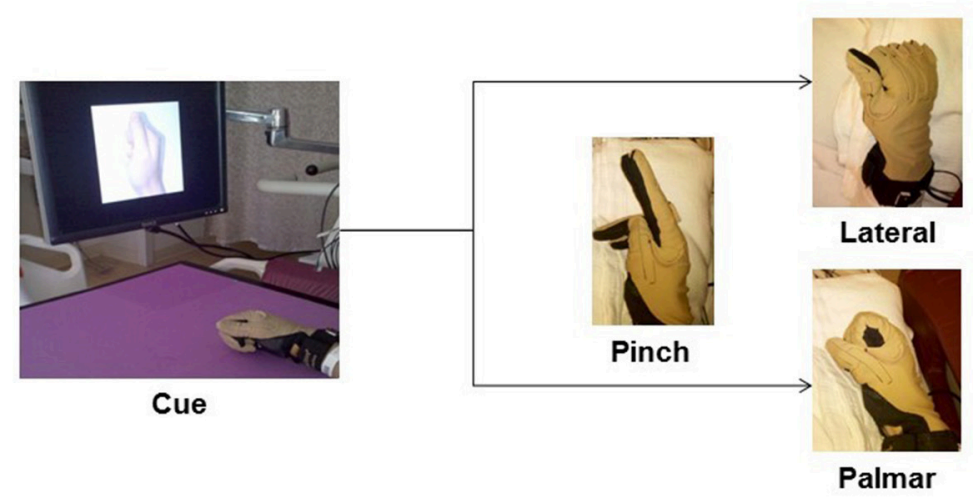

B

Palmar

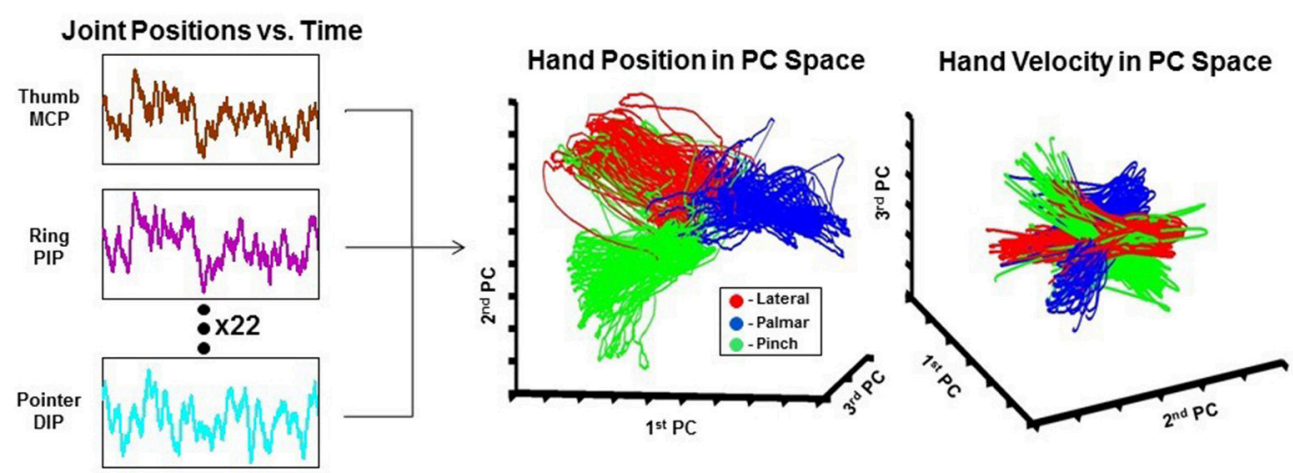

C

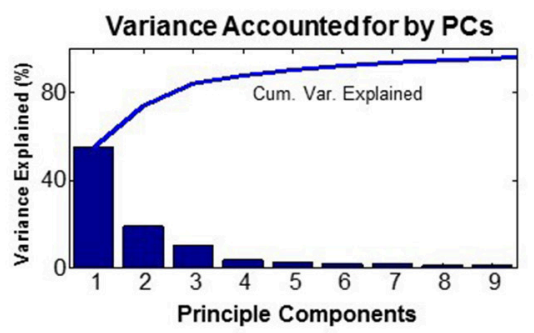

FIGURE 3 | Principal component analysis (PCA). The example reduces 22 joint-position variables of the wrist and fingers to 3 dimensions that represent the state of the hand. (A) Experimental task where the patient is cued to move his hand into one of the three configurations shown. (B) 22 independent variables of hand movement are recorded and reduced to 3 principle components (PCs). Results are plotted as hand position and hand velocity in 3-dimensional PC space. (C) Greater than $80 \%$ variance of hand movement is accounted for using only the first three PCs (Krucoff and Slutzky, 2011). MCP, metacarpophalangeal joint; PIP, proximal interphalangeal joint; DIP, distal interphalangeal joint.

scalp via a magnetic stimulator. Continuous low frequency repetitive stimuli ( $\leq 1 \mathrm{~Hz}$ rTMS) decreases excitability of targets areas (similar to LTD which is maximally evoked at $1 \mathrm{~Hz}$ ), while bursts of intermittent high frequency stimuli $(\geq 5 \mathrm{~Hz}$ rTMS) enhance excitability (similar to LTP with high frequency bursts) (Kobayashi and Pascual-Leone, 2003; Demirtas-Tatlidede et al., 2012; Shin et al., 2014). These techniques have been used to induce modulation across cortico-subcortical and corticocortical networks through trans-synaptic spread, resulting in distant but specific changes along functional networks. Evidence suggests long term effects from TMS may be related to modulation of NMDA glutamatergic receptors, similar to induction of LTP/LTD (reviewed in Villamar et al., 2012). If timed correctly, corresponding sensory inputs can be potentiated
(Stefan et al., 2000). Functional electrical stimulation (FES) of paralyzed muscles or electrical stimulation of the nervous system distal to the injury timed with voluntary effort has been shown to accelerate recovery in both SCI and stroke (Daly et al., 2006; Jung et al., 2009; Popovic et al., 2011; Kafri and Laufer, 2015).

\section{THE STATE OF THE ART IN NEURAL PROSTHESES AND BRAIN-MACHINE INTERFACES}

The first assistive BMI for patients with severe motor impairment was developed for patients with locked-in syndrome-a 


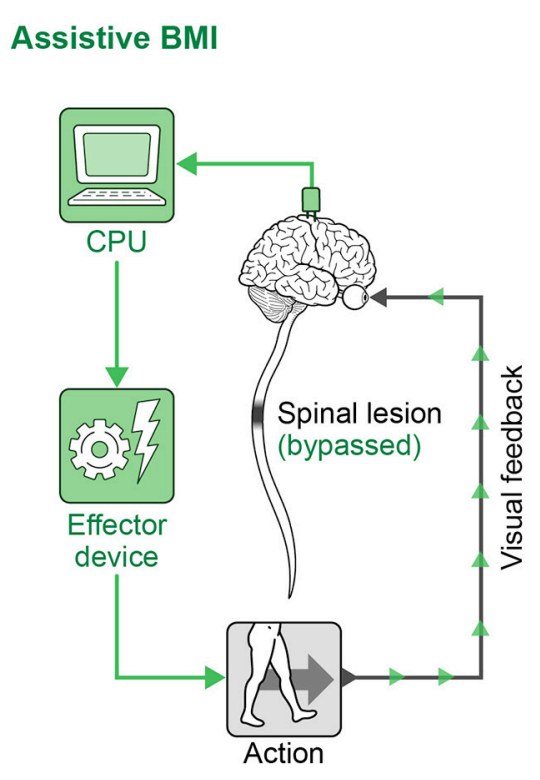

Rehabilitative BMI

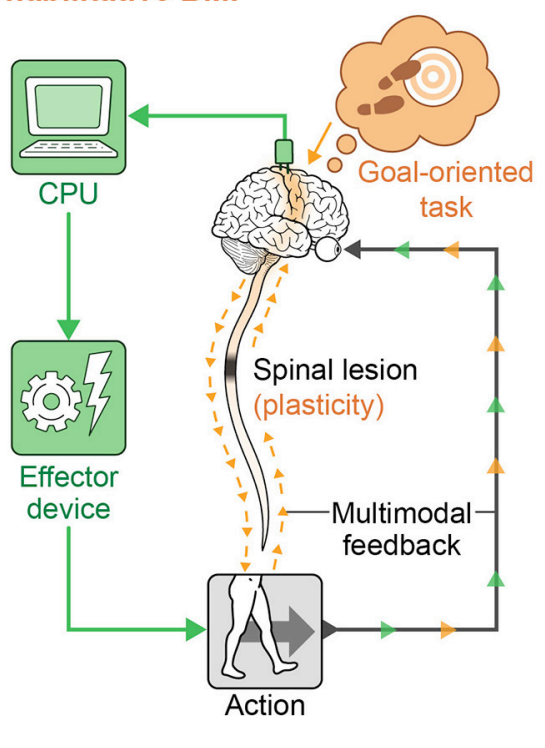

FIGURE 4 | Assistive vs. rehabilitative BMIs. The assistive BMI uses brain signals to bypass a neural lesion and generate an intended action. The rehabilitative BMI pairs goal-oriented tasks with positive feedback and works to re-activate lesioned circuits to create plasticity for long-lasting functional improvement.

condition where a patient is cognitively aware of his or her environment but is unable to move or make sounds (Kennedy and Bakay, 1998; Birbaumer et al., 1999). Birbaumer et al.'s device was an EEG-based system designed to translate purposeful slow cortical potentials (SCPs) into a binary selection of letters or words on a screen. Since then, EEG-based systems have advanced to move cursors on a screen in up to 3 dimensions (McFarland et al., 2010), open and close a hand orthosis (Ramos-Murguialday et al., 2012), provide limited FES-control of upper and lower extremities (King et al., 2015; Vidaurre et al., 2016), and ambulate a lower extremity exoskeleton (Donati et al., 2016); however, their potential is hindered due to inherently poor reliability, latency, signal variability, and generally non-intuitive nature (reviewed in Jackson and Zimmermann, 2012).

In non-invasive BMIs, six types of brain signals have been tested: sensori-motor rhythms (SMRs, 8-15 Hz, i.e., rolandic alpha or mu rhythm) (Pfurtscheller et al., 1992, 2006; Wolpaw and McFarland, 1994; McFarland et al., 2006), event-related potentials (ERPs) (Farwell and Donchin, 1988), SCPs (Birbaumer et al., 1999), steady-state visually or auditory evoked potentials (SSVEPs/SSAEPs) (Sakurada et al., 2013), concentration changes of oxy/deoxy hemoglobin using functional nearinfrared spectroscopy (fNIRS) (Sitaram et al., 2009; Mihara et al., 2013; Rea et al., 2014), and blood-oxygenation level dependent (BOLD)-contrast imaging using functional MRI (Weiskopf et al., 2003). Implantable BMIs utilize epidural, subdural, or intracortical electrodes. Epi- and subdural arrays record field potentials (FPs), while intracortical electrodes record APs (a.k.a. spikes) (reviewed in Soekadar et al., 2015). A summary of neural recording methods is provided in Figure 5.
Of all recording modalities, intracortical systems have demonstrated the most advanced control potential. Hochberg et al. provided initial evidence that a chronically tetraplegic human could operate a BMI using electrodes implanted into the arm area of M1 to drive a computer cursor on a screen (Hochberg et al., 2006). Several years later, that same group demonstrated brain control of a robotic arm to perform three-dimensional reach and grasp movements in two patients, including the ability to drink coffee from a bottle (Hochberg et al., 2012). Since then, intracortical BMIs have enabled brain-controlled typing (Jarosiewicz et al., 2015; Nuyujukian et al., 2016), driven seven degrees of freedom in a prosthetic limb at over 90\% accuracy (Collinger et al., 2013), restored voluntary movement and grasp via real-time FES to a monkey with a paralyzed hand (Moritz et al., 2008; Ethier et al., 2012), coordinated cervical intraspinal simulation to enact reach and grasp in the upper extremities (Zimmermann and Jackson, 2014), restored functional hand movement to a patient with quadriplegia (Bouton et al., 2016), and alleviated gait deficits in macaques with hemicord injuries via brain-controlled spinal epidural stimulation (Capogrosso et al., 2016). Additionally, intracortical electrodes distributed in more diffuse frontoparietal areas have enabled simultaneous bimanual control of avatar arms (Ifft et al., 2013).

To date, the only recording modalities stable enough to drive assistive BMIs over a prolonged period of time are implanted electrodes. Even here, the major concern with chronically implanted intracortical sensors is signal longevity. Microelectrode arrays (MEAs) face gliosis that begins in the first few months and can lead to failure at an average of 1 year (Barrese et al., 2013, 2016). Eventually, progressive meningeal fibrosis can encapsulate and elevate a microarray out of the 


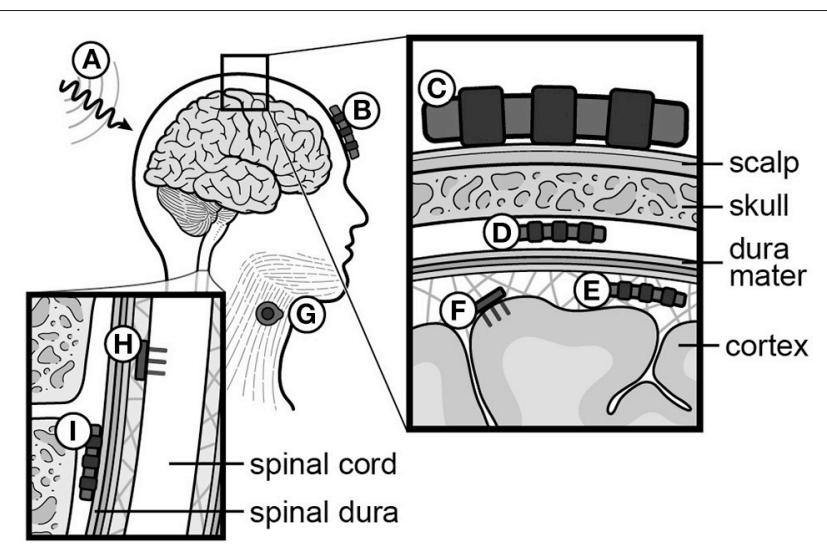

FIGURE 5 | Recording and stimulating modalities for neural signals. (A) Functional MRI (fMRI), (B) functional Near-Infrared Spectroscopy (fNIRS), (C) scalp electrodes (EEG), (D) epidural electrodes (FP), (E) subdural electrodes (ECoG), (F) intracortical electrodes (AP, or spikes), (G) muscle electrodes (EMG), (H) intraspinal electrodes (AP, or spikes), (I) spinal epidural electrodes (FP). EEG, electroencephalography; FP, field potential; ECoG, electrocorticography; AP, action potential; EMG, electromyography.

cortex. Foreign body reactions and reactive oxygen species lead to degradation of the materials over time. In the most commonly used MEA known as the Utah array (UEA), failure can be due to cracking of parylene, corrosion of platinum, and delamination of silicone elastomer (Barrese et al., 2013, 2016). Other intracortical recording techniques have been developed in non-human primate models that minimize cortical damage and have recorded stable signals for years, but these systems are not widely adopted and have not yet been demonstrated in human patients (Krüger et al., 2010; Schwarz et al., 2014).

This concern for longevity is one of the reasons ECoGbased systems have become increasingly popular, as there is evidence that FPs may have greater longevity and stability than spikes (Flint et al., 2013, 2016). Recently, a fully implantable ECoG system has been used to create a typing interface for a locked-in patient with ALS by decoding hand motor intention (Vansteensel et al., 2016), and another 64 channel completely implantable system has been CE marked in Europe for human use in BCI applications (Mestais et al., 2015). FPs recorded from the surface of the human motor cortex contain high gamma activity $(70-300 \mathrm{~Hz})$ and time domain features that can be used to decode continuous force, isometric pinch force, and muscle activity in finger flexors with high levels of accuracy (Crone et al., 2001; Flint et al., 2014). Hotson et al. recently utilized a high-density ECoG array over the motor cortex to achieve control of individual fingers on a prosthetic limb by a human subject with epilepsy (Hotson et al., 2016). ECoGbased systems have also been used as a mechanism to provide therapy to chronic stroke patients who would otherwise be unable to participate (Buch et al., 2008; Ramos-Murguialday et al., 2013; Gharabaghi et al., 2014b). In one example, a patient gained volitional control of a feedback device and engaged himself in repetitive, high-intensity exercises of finger pointing and wrist extension without the need for a therapist. He could simultaneously monitor his own ability to modulate his brain activity and receive immediate rewards for success, eventually improving the function of the targeted muscle (Gharabaghi et al., 2014c). Additionally, there is now evidence that epidural arrays can provide similar information to subdural arrays regarding finger kinematics, thus potentially providing a less invasive and equally viable option for such applications (Flint et al., 2017).

Other implanted devices include cortex-to-cortex BMIs that have been used to bridge damaged neural pathways directly. Guggenmos et al. showed that a neural prosthetic could help reconnect premotor to somatosensory cortex in an injured rat brain to restore reach and grasp functions to pre-lesion levels (Guggenmos et al., 2013). Other investigators have connected the brains of several animals into a single system, or "brainet," where the animals try to achieve a single objective using brain control only (Pais-Vieira et al., 2015; Ramakrishnan et al., 2015). Clinical applications for the latter remain to be established.

Novel methods for extracting brain signals are continually being developed. For example, Oxley et al. recently deployed an endovascular venous electrode array, or "stentrode," into a superficial cortical vein over the motor cortex in freely moving sheep for over 6 months. They report recording performance similar to epidural surface electrodes (Oxley et al., 2016). Clinical applicability of this device remains to be seen, however, and its use will likely be limited to recording from cortical areas near its deployment. Furthermore, implantation of the electrodes will contain the risks associated with angiographic deployment of a stent, including hemorrhage, thrombosis, stroke, and infection. Notably, many of these limitations and risks are shared with other implantable electrode systems.

Despite the success of cortically controlled motor prosthetic devices in animals, the translation into broad clinical applicability for human patients remains a challenge (reviewed in Patil and Turner, 2008; Turner et al., 2008; Nicolelis and Lebedev, 2009). Although rarely studied in the context of a motor BMI, subcortical regions such as the motor thalamus and subthalamic nucleus (STN) are also involved in motor planning and execution (Friehs et al., 2004; Patil et al., 2004; Hanson et al., 2012; Ryapolova-Webb et al., 2014). Deep brain stimulation (DBS) in these areas is approved by the United States Food and Drug Administration (FDA) for the treatment of Parkinson Disease and tremor, and it is generally well-tolerated. For these reasons, some researchers have suggested that chronic subcortical ensemble recordings may enhance the viability of subcortical BMI systems (Hanson et al., 2012; Ryapolova-Webb et al., 2014). Recordings from microwire arrays in awake patients undergoing deep brain stimulation found that $61 \%$ of neurons in the STN and $81 \%$ of ventralis oralis posterior (VOP) and ventralis intermedius (VIM) neurons modulate with gripping force, and that ensembles of 3-55 simultaneously recorded neurons contained sufficient information to predict gripping force (Patil et al., 2004). In other studies, after minutes of practice, patients have been able to bring a cursor to a target (Friehs et al., 2004). Additionally, modulations in firing rate of neurons in VOP, VIM, and STN have been shown represent target onset, movement onset/direction, and hand tremor (Hanson et al., 2012). 
In addition to brain signals, muscles proximal to an injury have been used as command signals in FES systems. For example, EMGs from muscles in the head and neck (e.g., platysma, trapezius, and auricularis) have been used to drive FES systems in patients with high cervical spinal cord injuries (Memberg et al., 2014). While these patients achieved enough voluntary control of their upper extremities to help with some activities of daily living (ADLs), their extremities did not reach antigravity strength, and there were serious limitations due to limb spasticity. Notably, EMG-based FES systems also do not work on patients who cannot voluntarily contract any muscles, and they require the use of pre-programmed stimulation patterns which can be non-intuitive (Memberg et al., 2014). Another major challenge facing BMIs on their way to useful clinical application is the difficulty in providing sensory or non-visual regulatory feedback to the user. While several groups have provided some level of information to a subject by stimulating the somatosensory cortex (London et al., 2008; Fagg et al., 2009; O’Doherty et al., 2009; Flesher et al., 2016), this technology remains in its infancy and is ripe for breakthrough. Improving artificial somatosensory feedback through intracortical microstimulation (ICMS), intraspinal stimulation, epidural spinal stimulation, or optogenetic stimulation are all efforts currently being undertaken (reviewed in Lebedev et al., 2011). However, perhaps the biggest hindrance to the large-scale development of BMIs is the lack of commercial appeal and marketability. Research and development costs of BMIs are enormous, and the market tends to be very niche and individualized. Until there is a large scale commercial interest, the greatest utility in advancing this field maybe in better understanding how to manipulate and rehabilitate the nervous system. While the cost of capable processors and electronics lessens with time, the cost of clinical trials remains a huge barrier to progress. Whether technological advancement, commercial interest, population demand, and clinical trial expense will evolve to allow for wide-scale testing and implementation remains to be seen (Patil and Turner, 2008). Also, for clinical viability, any interface needs to be reliable for a very long period of time (e.g., a decade), and, unfortunately, this remains a problem for virtually every studied neural implant except DBS electrodes. Future microelectrode arrays could address concerns about durability through improved insulation materials, inert electrode alloys, and/or incorporation of anti-inflammatory material along the lines of drug eluting stents (Barrese et al., 2016).

While largely outside the scope of this paper, interfaces for applications beyond motor recovery are also emerging. Devices designed to control medically refractory seizures are on the market. Neuromodulation for psychiatric illness is also currently being tested in many centers around the world, although results to date are mixed (Houeto et al., 2005; Mayberg et al., 2005; Greenberg et al., 2006). New targets for neuromodulation, including the fornix and septal area (Sweet et al., 2014), are under investigation for the treatment of Alzheimer's disease (Laxton et al., 2010). One can envision the development of neural interfaces for neuroprotection, memory (Hamani et al., 2008; Suthana et al., 2012), cognitive enhancement, concussion treatment, and sensory augmentation in the near future (reviewed in Laxton et al., 2013; Bick and Eskandar, 2016).

\section{NEUROREHABILITATION AND ELECTRICAL STIMULATION OF THE NERVOUS SYSTEM}

Given that injured cells of the CNS do not regenerate on their own, how can recovery be facilitated for patients with TBI, stroke, or SCI? Several avenues for therapy have been explored, including various physical rehabilitation paradigms (Wernig and Müller, 1992; Protas et al., 2001; Taub and Morris, 2001; Taub et al., 2002; Duncan et al., 2011; Harkema et al., 2012; Mackay-Lyons et al., 2013) and electrical stimulation modalities (Shik and Orlovsky, 1976; Dimitrijevic et al., 1998; Rattay et al., 2000; Carhart et al., 2004; Minassian et al., 2004, 2007; Levy et al., 2008; DeFina et al., 2010; Dy et al., 2010; Troyk et al., 2012; Gad et al., 2013a,b; Angeli et al., 2014; Gerasimenko et al., 2015a,b; Prochazka, 2016). Individually each of these areas has yielded only modest results; however, by combining and improving techniques, significant progress has been made (Carhart et al., 2004; reviewed in Breceda and Dromerick, 2013).

Physical therapy is the mainstay of virtually every neurorehabilitation program, and there have been several types of physical therapy studied. Examples of prominent physical therapy modalities are shown in Figure 6. For early stroke patients, constraint-induced movement therapy (CIMT) has been used to encourage use of the paretic limb by restraining the less affected one (Taub and Morris, 2001; Taub et al., 2002). This is done to avoid "learned non-use," as animal data has shown maladaptive changes and worse functional outcomes from allowing overcompensation with the less affected limb to dominate goal-directed tasks (Allred et al., 2005; Allred and Jones, 2008). Timing the application of CIMT appears to be crucial, however, as behavioral interventions employed too early after injury may be deleterious (Kozlowski et al., 1996). The mechanism of worse outcome in too-early therapy is likely related to glutamate-NMDA excitotoxicity due to over-engaging vulnerable tissue surrounding the injury site (see The Biology of Neurological Injury section above). Additionally, early intensive training with immunotherapy has been shown to induce hyperinnervation and aberrant growth, resulting in wrong circuit connectivity and impaired function in rat models of stroke (see Molecular Mechanisms of Neural Repair section above) (Wahl et al., 2014). Several studies have examined the efficacy of CIMT for motor recovery in human stroke patients with mixed results (Wolf et al., 2006; Dromerick et al., 2009; McIntyre et al., 2012), and the optimal timing for its application in human stroke patients is yet to be determined (reviewed in Lang et al., 2015).

Another commonly used physical therapy paradigm is partial weight-bearing therapy (PWBT), or body weight supported treadmill training (BWSTT) (Wernig and Müller, 1992; Protas et al., 2001; Duncan et al., 2011; Mackay-Lyons et al., 2013). This model has evolved from observations that spinalized animals on a moving treadmill can initiate and sustain full weightbearing stepping over different speeds and directions due to intrinsic changes in the locomotive rhythm generators of the spinal cord (Barbeau and Rossignol, 1987; reviewed in Wolpaw 


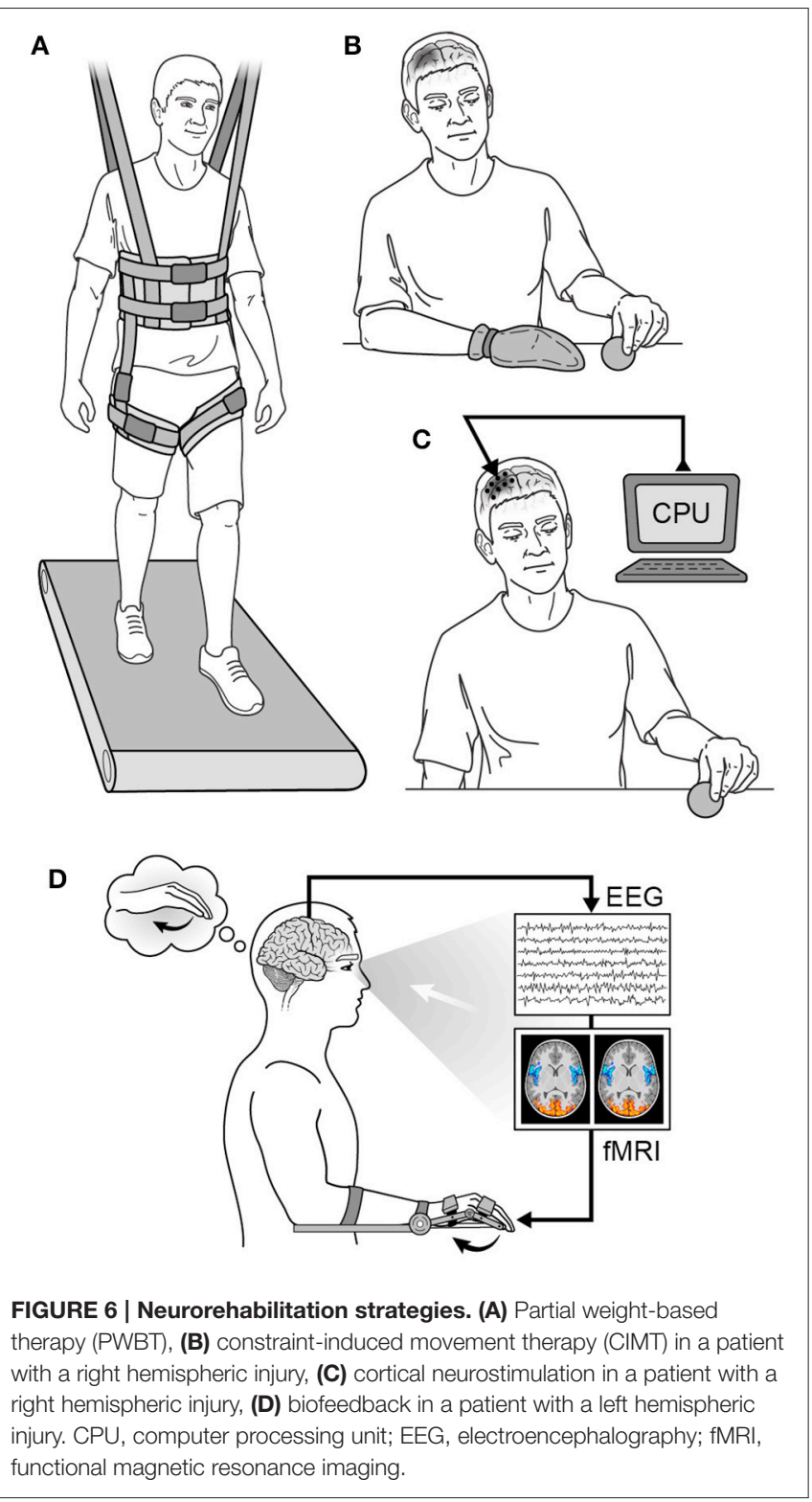

and Tennissen, 2001). When applied as a monotherapy to human stroke patients, benefits are largely comparable to those seen with other methods of physical therapy - the main value being increased cardiovascular endurance (Duncan et al., 2011; Mackay-Lyons et al., 2013). However, when used in patients with incomplete SCI either alone or in combination with FES and monoaminergic excitation, PWBT/BWSTT has been shown to facilitate locomotor function and decrease the reliance on assistive devices while improving coordination, speed, and endurance (Wernig and Müller, 1992; Protas et al., 2001; Harkema et al., 2012). In some cases, the benefits have not been limited to treadmill ambulation, but have been shown to be transferable to over-ground walking (Wernig et al., 1998; Carhart et al., 2004). In at least one patient with chronic incomplete SCI, intermittent PWBT alone was not sufficient to improve ambulation over ground; however, with the addition of epidural spinal stimulation, he was successful (Carhart et al., 2004).

Epidural spinal stimulation is one example of an emerging spinal modulation strategy to capture dormant but functional inter-neuronal pools distal to a spinal lesion and produce coordinated limb activity (Iwahara et al., 1992; Dimitrijevic et al., 1998; Sayenko et al., 2014; reviewed in Edgerton et al., 2004; Fong et al., 2009; Roy et al., 2012). Spinal stimulation to enhance motor performance in human patients with upper motor neuron disease (e.g., multiple sclerosis) was demonstrated as early as 1973 (Cook and Weinstein, 1973; Illis et al., 1976; Dooley and Sharkey, 19771978; Dimitrijevic et al., 1980, 2015), followed later by evidence that central pattern generators exist within the mammalian lumbosacral spinal cord that could be stimulated to produce locomotion (Grillner, 1985; Iwahara et al., 1992; Dimitrijevic et al., 1998; Minassian et al., 2007). Using electrical techniques to generate stepping in combination with extensive goal-directed physical therapy, patients with chronic and complete SCI have now shown the ability to develop positive functional plasticity and regain some voluntary control of lower extremity movement (Gad et al., 2015; Gerasimenko et al., 2015a,b). Other subjects with complete SCIs have regained the ability to selectively move their hips, knees, and ankles, as well as regain some coordination of flexor and extensor muscles (Sayenko et al., 2014; Dimitrijevic et al., 2015). Furthermore, some of these patients learned how to stand independently and activate lower limb musculature during partial weight-bearing stepping (Sayenko et al., 2014). In addition to attaining better lower extremity control, improvements in cardiovascular, temperature, bladder, and bowel control have been noted, as well as enhanced sexual function in some (Harkema et al., 2011; Angeli et al., 2014; Gad et al., 2015; Gerasimenko et al., 2015a,b). In other subjects, subthreshold epidural stimulation between L2 and S1, or direct stimulation of the pudendal nerve, has been shown to initiate micturition (Gad et al., 2014; McGee and Grill, 2014; McGee et al., 2015).

The mechanism by which complete and chronic SCI patients regain voluntary motor control of their lower extremities is currently unclear (reviewed in Kern et al., 2005). The fact that positive, lasting plasticity (up to years after training) can be induced suggests that there are likely subclinical surviving descending tracts in the injured spinal cord that are amenable to modulation and strengthening (Sherwood et al., 1992; Harkema et al., 2011; Angeli et al., 2014; Gerasimenko et al., 2015b). However, Van den Brand et al. showed that pairing goal-directed training with electrochemically enabled lumbosacral neurons (epidural stimulation with pharmacologic enhancement) can induce growth of de novo brainstem and intraspinal relays that re-enable voluntary control of locomotion in rats (van den Brand et al., 2012). As a control, they showed that automated treadmillrestricted training, which did not engage cortical neurons, failed to promote plasticity across the lesion or functional recovery. These results suggest that active, goal-directed training that engages task-specific cortical neurons is an essential component to recovery, and that its pairing with appropriate sensory cues (in this case, stepping gate) can lead to trans-lesional axonal sprouting and regained voluntary control of function (van den 
Brand et al., 2012). Interestingly, there is also evidence that spinal cord stimulation can replenish progenitor cells in the injured spinal cords of rat models (Becker et al., 2010), but this has not yet been explored in higher animals.

When used for SCI rehabilitation, epidural stimulation is often combined with monoamine therapy to increase the baseline excitatory state of distal functional elements and prime them for activation (Carhart et al., 2004; Harkema et al., 2011; van den Brand et al., 2012; Angeli et al., 2014; Wahl et al., 2014; Gerasimenko et al., 2015a,b). Neurons are known to release serotonin (5HT), norepinephrine (NE), and dopamine (DA) during locomotion within most laminae of lumbosacral segments (reviewed in van den Brand et al., 2015). These monoamines are thought to operate through volume neurotransmission (i.e., perisynaptic signal diffusion), and, along with epidural stimulation, have helped promote locomotion in both animal models and human patients with incomplete and complete spinal cord injuries (Carhart et al., 2004; Harkema et al., 2011; van den Brand et al., 2012; Angeli et al., 2014; Wahl et al., 2014; Gerasimenko et al., 2015a,b).

More intricate and invasive methods of stimulating and recording from the spinal cord are also being developed (Troyk et al., 2012; Gad et al., 2013a; Chang et al., 2014; Grahn et al., 2015; Minev et al., 2015; Mazurek et al., 2016; Prochazka, 2016). New generations of intraspinal microstimulator systems, including wireless ones, are being constructed to take advantage of this residual functional potential and plasticity. Older intraspinal stimulation technology was designed primarily for pain suppression, so there is optimism that these newer and more targeted devises will generate better outcomes than previously seen.

Direct brain stimulation as an adjunct to physical therapy has shown the ability to enhance functional recovery of reach and grasp tasks in rats to pre-lesion levels (Kleim et al., 2003; Guggenmos et al., 2013) and enhance cortical plasticity and functional status after stroke in squirrel monkeys (Plautz et al., 2003). This improvement appears to be induced by both reemergence of movement representation in peri-infarct areas as well as the emergence of new areas of representation (Nudo and Milliken, 1996; reviewed in Shin et al., 2014). After repeated stimuli, areas of movement representation have been seen to shift several microns and increase in size with a corresponding increase in spine density in pyramidal cell layers III and V (Nudo et al., 1990; Monfils et al., 2004). Stimulation to other areas of the brain has also gained interest for goals other than motor recovery. For example, deficits in learning and memory in rats after TBI has been improved by theta burst stimulation (TBS) of the fornix and hippocampus (Sweet et al., 2014). There is also human data supporting the use of subthreshold cortical stimulation for recovery after an ischemic infarct (Levy et al., 2008); however, recent data from phase III trials have been negative (Levy et al., 2016).

For patients with severe disorders of consciousness, median nerve stimulation (MNS) has been used to enhance oxygen perfusion to the brain and increase blood brain barrier permeability for medications intended to help stabilize the acute injury environment (Cooper et al., 2006; DeFina et al., 2010). MNS has also been found to increase DA levels, resulting in accelerated wakening from deep coma (Cooper et al., 2006). In 2010, DeFina et al. published an advanced care protocol (ACP) for the rehabilitation of patients in minimally conscious and vegetative states from TBI that involves sequential administration of an array of pharmaceuticals followed by specific interventions and treatments aimed at facilitating neuroplasticity (traditional occupational, physical, and speech therapy plus median nerve stimulation) (DeFina et al., 2010). Patients in this study also finished a 12 week course of pharmaceutical grade nutrients ("neutraceuticals") which resulted in a modest improvement in disability beyond standard treatment in literature controls.

New closed-loop stimulation (i.e., bio-feedback) paradigms are also being developed for patients who cannot participate in traditional therapy, including brain state dependent stimulation (BSDS) (Gharabaghi et al., 2014a). In 2014, Gharabaghi et al. published an experiment where transcranial magnetic stimulation (TMS) of the motor cortex and haptic feedback to the hand were controlled by sensorimotor desynchronization during motor-imagery in one healthy and one stroke subject with chronic hand paresis (Gharabaghi et al., 2014a). They found that BSDS increased the excitability of the stimulated motor cortex in both patients, an effect not observed in nonBSDS protocols. Both transcranial direct current and magnetic stimulation therapies are in early stages.

Another area of growing interest is robotic therapy, primarily for its ability to deliver highly intense and repetitive motor practice. There is evidence that for some applications, robotic therapy is at least non-inferior to traditional therapy (Reinkensmeyer et al., 2004; Lo et al., 2010; Milot et al., 2013). However, as it stands today, robotic therapy remains limited in its applications, largely because of its inability to individualize goal-directed rehabilitation paradigms suited to unique patient needs. Despite this challenge, robotic interfaces are actively becoming more sophisticated, and a wide range of strategies are now being used to improve whole body functions. For example, an advanced rehabilitative robot with the ability to assess individualized statistics regarding gait and balance stability has been demonstrated on a rat model (Dominici et al., 2012). This particular robot also contains a mode with locomotive capabilities that can go up stairs, as well as a training mode with epidural stimulation, repetitive training, and pharmacologic excitation built in. The latter mode has been shown to enable rats to achieve voluntary over-ground walking, stair walking, and precise paw placement after a stroke. Recently, training for a year with an EEG-based lower extremity exoskeleton and virtual reality leg simulations has been shown to improve somatic sensation and enable new voluntary motor control in the legs of previously chronic complete SCI patients, promoting some patients up to an incomplete paraplegia classification (Donati et al., 2016). As adaptive physiologic mechanisms improve and costs lessen, robotic therapy will likely become increasingly integral to rehabilitative strategies due to its ability to be applied in both a clinic and home setting (Cai et al., 2006; Reinkensmeyer et al., 2006; Courtine et al., 2008). 


\section{DISCUSSION AND INTEGRATION}

There are many reasons to be optimistic about the potential for human nervous system repair. For the first time in history we are seeing patients with chronic and complete spinal cord injuries voluntarily move their legs (Dy et al., 2010; Angeli et al., 2014; Gerasimenko et al., 2015b; Donati et al., 2016). Advances in modern neurobiological, neuroengineering, and neurorehabilitation strategies have provided hope for better outcomes, and the synergistic potential of integrated strategies is only beginning to be realized. In fact, there is a substantial amount of evidence reviewed here that suggests multi-disciplinary approaches might not only be helpful, but will be critical for any technique to realize its full therapeutic capability. While the essential nature of many rehabilitation strategies remains a subject of debate, well-timed, goal-directed therapy and some form of associated positive feedback mechanism appear to be necessary components of therapeutic paradigms aimed at generating axonal sprouting and lasting functional improvement (van den Brand et al., 2012; Wahl et al., 2014). This is a profound realization, largely because the abstract concept of how conscious agency relates to neuroanatomical principles of circuitry and guidance remains a mystery (reviewed in Brogaard and Gatzia, 2016; Koch et al., 2016; Sandberg et al., 2016), and data presented in this article suggests that they must be more intimately connected than previously appreciated. Perhaps this relationship can be further interrogated by studying the early development of the nervous system when goal-directed development (e.g., learning to walk or use one's hands) naturally leads to innervation and the establishment of a robust and functional nervous system. On a practical level, the principle of cortically-based intent driving axonal sprouting has at least two important consequences: (1) that patients who suffer from disorders of consciousness (e.g., comatose or vegetative patients) may need completely different therapeutic strategies to attain neural repair than those who have intact consciousness systems, and (2) that experiments which have failed in vitro may still be viable therapies when integrated into a macroscopic framework that includes conscious intent and goal-directed therapy with a mechanism for positive feedback.

For patients with disorders of consciousness, perhaps more proximally-based interventions, e.g., cortical stimulation, will find a way to substitute for active participation in rehabilitation. Pairing this stimulation with other feedback mechanisms [e.g., peripheral nerve stimulation and/or passive movement (via exoskeleton, robotic therapy, or physical therapy)] could capitalize on PAS principles discussed in The Neurophysiology Underlying Brain-Machine and Neural Interface Training section. Furthermore, pharmacologic therapy aimed at promoting alertness should be included in treatment strategies.

Another consequence of this theory is that new biological approaches still largely in the in vitro stage may need to be applied with goal-directed rehabilitation paradigms to realize their therapeutic potential, and may fail in isolation. Perhaps the clearest support for this claim was the demonstration by Wahl et al. in 2014 of nearly full recovery of skilled forelimb function by rats with large strokes by giving intrathecal injection of an antibody against Nogo-A followed by intensive taskspecific training (Wahl et al., 2014). This study demonstrated that sequential application of drug then training was necessary to show benefit, and when immunotherapy and forced-use training were combined simultaneously, functional outcome was worse than either individually. Furthermore, proper combination therapy demonstrated far better results than individual treatments alone. These results serve as evidence that the timing of therapeutic interventions is critical in neurorehabilitation, and that failed treatment strategies pursued in isolation may not, in fact, be futile; instead, they may need to be applied under a different set of circumstances or synergistically with other macro level treatments. This principle could also apply to stem cells (Mothe and Tator, 2012), gene therapies (Warren Olanow et al., 2015), optogenetics (reviewed in Jarvis and Schultz, 2015), neuronal transplantation (Furlanetti et al., 2015), and novel biological or immunotherapies (Maier et al., 2009; Alilain et al., 2011). While details of these treatments remain largely outside the scope of this paper, unfortunately they are all still far from clinical implementation. When ready for rigorous trials, however, evidence presented here suggests that well-timed task-specific physical therapy accompanied by mechanisms like neurostimulation and monoaminergic excitation should be utilized to facilitate their success. Combinations of biological therapies, e.g., stem cell and immunotherapies, may also yield benefit, even if the success of individual applications is found to be modest; in this review, we have shown multiple examples that failure of an individual therapy does not preclude its success in the right context (Benowitz and Yin, 2007; Zai et al., 2011; Wahl et al., 2014). Researchers should also consider delivering local therapies when the extracellular milieu is the most conducive to axonal sprouting and rewiring (i.e., in the first few weeks after injury), as the subacute inflammatory environment may be more conducive to assimilating signals for plasticity and growth than at other times (see The Biology of Neurological Injury and The Physiology of Recovery from Neurological Injury sections) (Shetty and Turner, 1995; Nahmani and Turrigiano, 2014). Since trials for these therapies can carry a very high financial burden and a negative trial may do serious harm to an otherwise potentially viable strategy, the incorporation of the proper macroscopic framework to the application of micro techniques may prove essential for success.

Until complete neurological repair is achievable, optimizing the timing of a variety of treatments and tailoring therapies to different phases of injury and recovery remains the gold standard approach (Kleim and Jones, 2008; Pekna et al., 2012). In American hospitals, standard of care during the acute phase of neurological injury aims to stabilize the injury and prevent further loss of tissue through (1) the initiation of hypothermia after cardiac arrest, (2) the maintenance of neural perfusion pressures after TBI or SCI, (3) the recannulation of occluded vessel(s) after stroke by thrombectomy or thrombolysis, or (4) surgery to evacuate mass lesions or decompress edematous tissue. Once stabilized, however, when and how best to apply pharmaceutical, rehabilitation, and neurostimulation strategies to aid in neural repair needs rigorous study (reviewed in 
Lang et al., 2015). While certain biological manipulations discussed in previous sections have shown promise in the lab (e.g., multiple NgR deletions, anti-NogoA antibodies, ionosine application, CAST/Ei knockouts), translation to bedside applications remains a challenge. Furthermore, generating axonal regrowth on its own does not ensure restoration of function (see Molecular Mechanisms of Neural Repair section). Also notable in clinical applications is the relative paucity of biomarkers that might help drive prognosis and diagnose phases of injury/recovery, as well as the large discrepancy between known mechanisms of injury-repair and viable options for intervention (reviewed in Hergenroeder et al., 2008; DeFina et al., 2009; Zetterberg et al., 2013). Now that outcomes may start improving, it would be interesting to monitor known markers through improved recovery periods, as well as to search for new ones in the hopes of helping inform the timing and selection of therapeutic applications. Perhaps by combining new developments in the neurobiology lab with the essential elements of neurological rehabilitation, neural simulation, and the concept of multi-disciplinary intervention on micro- and macroscopic levels, success will be found where previously promising therapies have failed (Alilain et al., 2011; Warren Olanow et al., 2015; Levy et al., 2016).

\section{CONCLUSION}

Researchers have long been developing ways to improve the quality of life for patients who suffer from SCI, stroke, and other neurological disorders classically categorized as permanent. Several disciplines, namely neurobiology, neuro-engineering, and neurorehabilitation, have all made great strides. However, the path to achieving complete neurologic recovery for human patients remains remote and complex. Nonetheless, patients are now starting to show recovery beyond that which was previously thought possible. This paper examined the most recent advances in the biology of neurological injury, molecular mechanisms of neural repair, physiology of neurological recovery, neurophysiology underlying brain-machine and neural interface training, state of the art in neural and brain-machine interfaces, neurorehabilitation strategies, and ideas for how to integrate future research. Furthermore, we have identified key elements of repair strategies that should be included in these studies. As the development of immunotherapies, electrical stimulation, neural interfaces, stem cells, optogenetics, and gene therapies advance, their reparative potential may only be realized by integrating them into a rehabilitation framework

\section{REFERENCES}

Alilain, W. J., Horn, K. P., Hu, H., Dick, T. E., and Silver, J. (2011). Functional regeneration of respiratory pathways after spinal cord injury. Nature 475, 196-200. doi: 10.1038/nature10199

Allred, R. P., and Jones, T. A. (2008). Maladaptive effects of learning with the less-affected forelimb after focal cortical infarcts in rats. Exp. Neurol. 210, 172-181. doi: 10.1016/j.expneurol.2007. 10.010 that includes conscious intention and positive neural feedback. Special attention should be paid to timing, sequence, and dose of therapy. Hopefully, these concepts will help usher in the next frontier of nervous system recovery.

\section{AUTHOR CONTRIBUTIONS}

MK, SR, MS, VE, and DT all contributed substantially to the intellectual property of this project. Each author either drafted or revised the document critically multiple times, and each has given his final approval of the version to be published. Furthermore, each author agrees to be accountable for all aspects of the work.

\section{FUNDING}

MK is supported by a grant from the National Institute of Neurological Disorders and Stroke (NINDS; R25, 5R25NS065731-08). MS is supported by grants from the National Institute of Health (NIH; K08NS060223 and R01NS094748), Paralyzed Veterans of America, Brain Research Foundation, Doris Duke Charitable Foundation, and Northwestern Memorial Foundation (Dixon Translational Research Grant). VE is supported by a grants from the National Institute of Biomedical Imaging and Bioengineering (NIBIB; U01EB007615, U01EB015521, R43EB017641, and R43EB018232), Paralyzed Veterans of America, WalkAbout Foundation, Christopher \& Dana Reeve Foundation, and Broccoli Foundation. DT is supported by grants from the NIH (R21, AG051103; RO1, NS079312; R21, NS084176; and R37, NS040894) and Veteran's Affairs (VA; VA I21, BX003023; and VA I21, RX002223).

\section{ACKNOWLEDGMENTS}

This work was inspired by the 2016 Research Update in Neuroscience for Neurosurgeons (RUNN) course, so a special thanks is due to course directors Allan Friedman, M.D. and Richard Friedlander, M.D. for organizing a stimulating curriculum. Thanks to course coordinator Karen Koenig for her hard work and display of hospitality. Another thanks to the distinguished lecturers, especially Andrew Schwartz, Ph.D., for their inspiration. Thanks also to Lee Miller, Ph.D., for his persistent willingness to collaborate and mentor, and to Larry Benowitz, Ph.D., for his inspiration and collaboration. And thanks to Miguel Nicolelis, M.D., Ph.D., Laura Oliveira, M.D., and Mikhail Lebedev, Ph.D., for their continued mentorship and support. Figures 1, 2, 4-6 were illustrated by Lauren Halligan at Duke University.

Allred, R. P., Maldonado, M. A., Hsu And, J. E., and Jones, T. A. (2005). Training the less-affected forelimb after unilateral cortical infarcts interferes with functional recovery of the impaired forelimb in rats. Restor. Neurol. Neurosci. 23, 297-302.

Alvarez-Buylla, A., and Lim, D. (2004). For the long run: maintaining germinal niches in the adult brain. Neuron 41, 683-686. doi: 10.1016/S0896-6273(04)00111-4

Ang, K. K., Guan, C., Chua, K. S. G., Phua, K. S., Wang, C., Chin, Z. Y., et al. (2013). A clinical study of motor imagery BCI performance in stroke by including 
calibration data from passive movement. Conf. Proc. IEEE Eng. Med. Biol. Soc. 2013, 6603-6606. doi: 10.1109/EMBC.2013.6611069

Angeli, C. A., Edgerton, V. R., Gerasimenko, Y. P., and Harkema, S. J. (2014). Altering spinal cord excitability enables voluntary movements after chronic complete paralysis in humans. Brain 137, 1394-1409. doi: 10.1093/brain/awu038

Arvidsson, A., Collin, T., Kirik, D., Kokaia, Z., and Lindvall, O. (2002). Neuronal replacement from endogenous precursors in the adult brain after stroke. Nat. Med. 8, 963-970. doi: 10.1038/nm747

Baldwin, K. T., Carbajal, K. S., Segal, B. M., and Giger, R. J. (2015). Neuroinflammation triggered by $\beta$-glucan/dectin-1 signaling enables CNS axon regeneration. Proc. Natl. Acad. Sci. U.S.A. 112, 2581-2586. doi: 10.1073/pnas.1423221112

Barbeau, H., and Rossignol, S. (1987). Recovery of locomotion after chronic spinalization in the adult cat. Brain Res. 412, 84-95. doi: 10.1016/0006-8993(87)91442-9

Barrese, J. C., Aceros, J., and Donoghue, J. P. (2016). Scanning electron microscopy of chronically implanted intracortical microelectrode arrays in non-human primates. J. Neural Eng. 13:26003. doi: 10.1088/1741-2560/13/2/026003

Barrese, J. C., Rao, N., Paroo, K., Triebwasser, C., Vargas-Irwin, C., Franquemont, L., et al. (2013). Failure mode analysis of silicon-based intracortical microelectrode arrays in non-human primates. J. Neural Eng. 10:66014. doi: 10.1088/1741-2560/10/6/066014

Becker, D., Gary, D. S., Rosenzweig, E. S., Grill, W. M., and McDonald, J. W. (2010). Functional electrical stimulation helps replenish progenitor cells in the injured spinal cord of adult rats. Exp. Neurol. 222, 211-218. doi: 10.1016/j.expneurol.2009.12.029

Bei, F., Lee, H. H., Liu, X., Gunner, G., Jin, H., Ma, L., et al. (2016). Restoration of visual function by enhancing conduction in regenerated axons. Cell 164, 219-232. doi: 10.1016/j.cell.2015.11.036

Benowitz, L. I., and Carmichael, S. T. (2010). Promoting axonal rewiring to improve outcome after stroke. Neurobiol. Dis. 37, 259-266. doi: 10.1016/j.nbd.2009.11.009

Benowitz, L. I., and Popovich, P. G. (2011). Inflammation and axon regeneration. Curr. Opin. Neurol. 24, 577-583. doi: 10.1097/WCO.0b013e32834c208d

Benowitz, L. I., and Yin, Y. (2007). Combinatorial treatments for promoting axon regeneration in the CNS: strategies for overcoming inhibitory signals and activating neurons' intrinsic growth state. Dev. Neurobiol. 67, 1148-1165. doi: 10.1002/dneu.20515

Benowitz, L., and Yin, Y. (2008). Rewiring the injured CNS: Lessons from the optic nerve. Exp. Neurol. 209, 389-398. doi: 10.1016/j.expneurol.2007. 05.025

Bernstein, D. R., and Stelzner, D. J. (1983). Plasticity of the corticospinal tract following midthoracic spinal injury in the postnatal rat. J. Comp. Neurol. 221, 382-400. doi: 10.1002/cne.902210403

Bhullar, I. S., Johnson, D., Paul, J. P., Kerwin, A. J., Tepas, J. J., and Frykberg, E. R. (2014). More harm than good: antiseizure prophylaxis after traumatic brain injury does not decrease seizure rates but may inhibit functional recovery. J. Trauma Acute Care Surg. 76, 54-60. doi: 10.1097/TA.0b013e3182 aafd15

Bick, S. K., and Eskandar, E. N. (2016). Neuromodulation for restoring memory. Neurosurg. Focus 40:E5. doi: 10.3171/2016.3.FOCUS162

Bienenstock, E. L., Cooper, L. N., and Munro, P. W. (1982). Theory for the development of neuron selectivity: orientation specificity and binocular interaction in visual cortex. J. Neurosci. 2, 32-48.

Birbaumer, N., Ghanayim, N., Hinterberger, T., Iversen, I., Kotchoubey, B., Kübler, A., et al. (1999). A spelling device for the paralysed. Nature 398, 297-298. doi: $10.1038 / 18581$

Bouton, C. E., Shaikhouni, A., Annetta, N. V., Bockbrader, M. A., Friedenberg, D. A., Nielson, D. M., et al. (2016). Restoring cortical control of functional movement in a human with quadriplegia. Nature 533, 247-250. doi: 10.1038/nature 17435

Breakspear, M., and Stam, C. J. (2005). Dynamics of a neural system with a multiscale architecture. Philos. Trans. R. Soc. Lond. B Biol. Sci. 360, 1051-1074. doi: 10.1098/rstb.2005.1643

Breceda, E. Y., and Dromerick, A. W. (2013). Motor rehabilitation in stroke and traumatic brain injury: stimulating and intense. Curr. Opin. Neurol. 26, 595-601. doi: 10.1097/WCO.0000000000000024
Bregman, B. S., Kunkel-Bagden, E., Schnell, L., Dai, H. N., Gao, D., and Schwab, M. E. (1995). Recovery from spinal cord injury mediated by antibodies to neurite growth inhibitors. Nature 378, 498-501. doi: 10.1038/378498a0

Brogaard, B., and Gatzia, D. E. (2016). What can neuroscience tell us about the hard problem of consciousness? Front. Neurosci. 10:395. doi: 10.3389/fnins. 2016.00395

Buch, E., Weber, C., Cohen, L. G., Braun, C., Dimyan, M. A., Ard, T., et al. (2008). Think to move: a neuromagnetic brain-computer interface (BCI) system for chronic stroke. Stroke 39, 910-917. doi: 10.1161/STROKEAHA.107.505313

Bulinski, J. C., Ohm, T., Roder, H., Spruston, N., Turner, D. A., and Wheal, H. V. (1998). Changes in dendritic structure and function following hippocampal lesions: correlations with developmental events? Prog. Neurobiol. 55, 641-650. doi: 10.1016/s0301-0082(98)00023-9

Cai, L. L., Fong, A. J., Otoshi, C. K., Liang, Y., Burdick, J. W., Roy, R. R., et al. (2006). Implications of assist-as-needed robotic step training after a complete spinal cord injury on intrinsic strategies of motor learning. J. Neurosci. 26, 10564-10568. doi: 10.1523/JNEUROSCI.2266-06.2006

Capogrosso, M., Milekovic, T., Borton, D., Wagner, F., Martin Moraud, E., Mignardot, J.-B., et al. (2016). A brain-spinal interface alleviating gait deficits after spinal cord injury in primates. Nature 539, 284-288. doi: 10.1038 /nature20118

Carhart, M. R., He, J., Herman, R., D’Luzansky, S., and Willis, W. T. (2004), Epidural spinal-cord stimulation facilitates recovery of functional walking following incomplete spinal-cord injury. IEEE Trans. Neural Syst. Rehabil. Eng. 12, 32-42. doi: 10.1109/TNSRE.2003.822763

Carmena, J. M., Lebedev, M. A., Crist, R. E., O’Doherty, J. E., Santucci, D. M., Dimitrov, D. F., et al. (2003). Learning to control a brainmachine interface for reaching and grasping by primates. PLoS Biol. 1:E42. doi: 10.1371/journal.pbio.0000042

Carmichael, S. T., Archibeque, I., Luke, L., Nolan, T., Momiy, J., and Li, S. (2005). Growth-associated gene expression after stroke: evidence for a growth-promoting region in peri-infarct cortex. Exp. Neurol. 193, 291-311. doi: 10.1016/j.expneurol.2005.01.004

Carmichael, S. T., and Chesselet, M.-F. (2002). Synchronous neuronal activity is a signal for axonal sprouting after cortical lesions in the adult. J. Neurosci. 22, 6062-6070.

Carson, R. G., and Kennedy, N. C. (2013). Modulation of human corticospinal excitability by paired associative stimulation. Front. Hum. Neurosci. 7:823. doi: 10.3389/fnhum.2013.00823

Chang, C. W., Lo, Y. K., Gad, P., Edgerton, R., and Liu, W. (2014). Design and fabrication of a multi-electrode array for spinal cord epidural stimulation. Conf. Proc. IEEE Eng. Med. Biol. Soc. 2014, 6834-6837. doi: 10.1109/EMBC.2014.6945198

Chen, D. F., Schneider, G. E., Martinou, J., and Tonegawa, S. (1997). Bcl-2 promotes regeneration of severed axons in mammalian CNS. Nature 385, 434-439. doi: 10.1038/385434a0

Chen, P., Goldberg, D. E., Kolb, B., Lanser, M., Benowitz, L. I., Chen, P., et al. (2002). Inosine induces axonal rewiring and behavioral outcome after stroke. Proc. Natl. Acad. Sci. U.S.A. 99, 9031-9036. doi: 10.1073/pnas.132076299

Cherian, A., Krucoff, M. O., and Miller, L. E. (2011). Motor cortical prediction of EMG: evidence that a kinetic brain-machine interface may be robust across altered movement dynamics. J. Neurophysiol. 106, 564-575. doi: 10.1152/jn.00553.2010

Collinger, J. L., Wodlinger, B., Downey, J. E., Wang, W., Tyler-Kabara, E. C., Weber, D. J., et al. (2013). High-performance neuroprosthetic control by an individual with tetraplegia. Lancet 381, 557-564. doi: 10.1016/S0140-6736(12)61816-9

Cook, A. W., and Weinstein, S. P. (1973). Chronic dorsal column stimulation in multiple sclerosis. Preliminary report. N. Y. State J. Med. 73, 2868-2872.

Cooper, E. B., Scherder, E. J., and Cooper, J. B. (2006). Electrical treatment of reduced consciousness: experience with coma and Alzheimer's disease. Neuropsychol. Rehabil. 15, 389-405. doi: 10.1080/09602010443000317

Cooper, L. N., and Bear, M. F. (2012). The BCM theory of synapse modification at 30: interaction of theory with experiment. Nat. Rev. Neurosci. 13, 798-810. doi: $10.1038 / \mathrm{nrn} 3353$

Cooper, S. J. (2005). Donald O. Hebb's synapse and learning rule: a history and commentary. Neurosci. Biobehav. Rev. 28, 851-874. doi: 10.1016/j.neubiorev.2004.09.009 
Courtine, G., Song, B., Roy, R. R., Zhong, H., Herrmann, J. E., Ao, Y., et al. (2008). Recovery of supraspinal control of stepping via indirect propriospinal relay connections after spinal cord injury. Nat. Med. 14, 69-74. doi: 10.1038/nm1682

Crone, N. E., Boatman, D., Gordon, B., Hao, L., Adrian, E. D., Matthews, B. H. C., et al. (2001). Induced electrocorticographic gamma activity during auditory perception. Clin. Neurophysiol. 112, 565-582. doi: 10.1016/S1388-2457(00)00545-9

Curt, A., Van Hedel, H. J. A., Klaus, D., and Dietz, V. (2008). Recovery from a spinal cord injury: significance of compensation, neural plasticity, and repair. J. Neurotrauma 25, 677-685. doi: 10.1089/neu.2007.0468

Dachir, S., Shabashov, D., Trembovler, V., Alexandrovich, A. G., Benowitz, L. I., and Shohami, E. (2014). Inosine improves functional recovery after experimental traumatic brain injury. Brain Res. 1555, 78-88. doi: 10.1016/j.brainres.2014.01.044

Daly, J. J., Roenigk, K., Holcomb, J., Rogers, J. M., Butler, K., Gansen, J., et al. (2006). A randomized controlled trial of functional neuromuscular stimulation in chronic stroke subjects. Stroke 37, 172-178. doi: 10.1161/01.STR.0000195129.95220.77

Dancause, N. (2005). Extensive cortical rewiring after brain injury. J. Neurosci. 25, 10167-10179. doi: 10.1523/JNEUROSCI.3256-05.2005

Dancause, N., and Nudo, R. (2011). Shaping plasticity to enhance recovery after injury Numa. Prog. Brain Res. 192, 273-295. doi: 10.1016/B978-0-444-53355-5.00015-4

DeFina, P. A., Fellus, J., Thompson, J. W., Eller, M., Moser, R. S., Frisina, P. G., et al. (2010). Improving outcomes of severe disorders of consciousness. Restor. Neurol. Neurosci. 28, 769-780. doi: 10.3233/RNN-2010-0548

DeFina, P., Fellus, J., Polito, M. Z., Thompson, J. W., Moser, R. S., and DeLuca, J. (2009). The new neuroscience frontier: promoting neuroplasticity and brain repair in traumatic brain injury. Clin. Neuropsychol. 23, 1391-1399. doi: 10.1080/13854040903058978

de Lima, S., Habboub, G., and Benowitz, L. I. (2012a). Combinatorial therapy stimulates long-distance regeneration, target reinnervation, and partial recovery of vision after optic nerve injury in mice. Int. Rev. Neurobiol. 106, 153-172. doi: 10.1016/B978-0-12-407178-0.00007-7

de Lima, S., Koriyama, Y., Kurimoto, T., Oliveira, J. T., Yin, Y., Li, Y., et al. (2012b). Full-length axon regeneration in the adult mouse optic nerve and partial recovery of simple visual behaviors. Proc. Natl. Acad. Sci. U.S.A. 109, 9149-9154. doi: 10.1073/pnas.1119449109

Demirtas-Tatlidede, A., Vahabzadeh-Hagh, A. M., Bernabeu, M., Tormos, J. M., and Pascual-Leone, A. (2012). Noninvasive brain stimulation in traumatic brain injury. J. Head Trauma Rehabil. 27, 274-292. doi: 10.1097/HTR.0b013e318217df55

Dickendesher, T. L., Baldwin, K. T., Mironova, Y. A., Koriyama, Y., Raiker, S. J., Askew, K. L., et al. (2012). NgR1 and NgR3 are receptors for chondroitin sulfate proteoglycans. Nat. Neurosci. 15, 703-712. doi: 10.1038/nn.3070

Dimitrijevi,ć, M. R., and Nathan, P. W. (1967). Studies of spasticity in man. I. Some features of spasticity. Brain 90, 1-30.

Dimitrijevic, M. R., Danner, S. M., and Mayr, W. (2015). Neurocontrol of movement in humans with spinal cord injury. Artif. Organs 39, 823-833. doi: 10.1111 /aor.12614

Dimitrijevic, M. R., Dimitrijevic, M. M., Sherwood, A. M., and Faganel, J. (1980). Neurophysiological evaluation of chronic spinal cord stimulation in patients with upper motor neuron disorders. Int. Rehabil. Med. 2, 82-85. doi: $10.3109 / 09638288009163962$

Dimitrijevic, M. R., Gerasimenko, Y., and Pinter, M. M. (1998). Evidence for a spinal central pattern generator in humans. Ann. N. Y. Acad. Sci. 860, 360-376. doi: 10.1111/j.1749-6632.1998.tb09062.x

Doetsch, F., Caillé, I., Lim, D. A., García-Verdugo, J. M., and Alvarez-Buylla, A. (1999). Subventricular zone astrocytes are neural stem cells in the adult mammalian brain. Cell 97, 703-716. doi: 10.1016/S0092-8674(00)80783-7

Dominici, N., Keller, U., Vallery, H., Friedli, L., van den Brand, R., Starkey, M., et al. (2012). Versatile robotic interface to evaluate, enable and train locomotion and balance after neuromotor disorders. Nat. Med. 18, 1142-1149. doi: $10.1038 / \mathrm{nm} .2845$

Donati, A. R., Shokur, S., Morya, E., Campos, D. S., Moioli, R. C., Gitti, C. M., et al. (2016). Long-term training with a brain-machine interface-based gait protocol induces partial neurological recovery in paraplegic patients. Sci. Rep. 6:30383. doi: $10.1038 /$ srep30383
Donoghue, J. P. (2008). Bridging the brain to the world: a perspective on neural interface systems. Neuron 60, 511-521. doi: 10.1016/j.neuron.2008. 10.037

Dooley, D. M., and Sharkey, J. (1977-1978). Electrostimulation of the nervous system for patients with demyelinating and degenerative diseases of the nervous system and vascular diseases of the extremities. Appl. Neurophysiol. 40, 208-217.

Dromerick, A. W., Lang, C. E., Birkenmeier, R. L., Wagner, J. M., Miller, J. P., Videen, T. O., et al. (2009). Very early constraint-induced movement during stroke rehabilitation (VECTORS): a single-center RCT. Neurology 73, 195-201. doi: 10.1212/WNL.0b013e3181ab2b27

Duncan, P. W., Sullivan, K. J., Behrman, A. L., Azen, S. P., Wu, S. S., Nadeau, S. E., et al. (2011). Body-weight-supported treadmill rehabilitation after stroke. $N$. Engl. J. Med. 364, 2026-2036. doi: 10.1056/NEJMoa1010790

Dy, C. J., Gerasimenko, Y. P., Edgerton, V. R., Dyhre-Poulsen, P., Courtine, G., and Harkema, S. J. (2010). Phase-dependent modulation of percutaneously elicited multisegmental muscle responses after spinal cord injury. J. Neurophysiol. 103, 2808-2820. doi: 10.1152/jn.00316.2009

Edgerton, V. R., Tillakaratne, N. J., Bigbee, A. J., de Leon, R. D., and Roy, R. R. (2004). Plasticity of the spinal neural circuitry after injury*. Annu. Rev. Neurosci. 27, 145-167. doi: 10.1146/annurev.neuro.27.070203.144308

Eom, J.-W., Lee, J.-M., Koh, J.-Y., and Kim, Y.-H. (2016). AMP-activated protein kinase contributes to zinc-induced neuronal death via activation by LKB1 and induction of Bim in mouse cortical cultures. Mol. Brain 9, 14. doi: 10.1186/s13041-016-0194-6

Ethier, C., Gallego, J. A., and Miller, L. (2015). Brain-controlled neuromuscular stimulation to drive neural plasticity and functional recovery. Curr. Opin. Neurobiol. 33, 95-102. doi: 10.1016/j.conb.2015.03.007

Ethier, C., Oby, E. R., Bauman, M. J., and Miller, L. E. (2012). Restoration of grasp following paralysis through brain-controlled stimulation of muscles. Nature 485, 368-371. doi: 10.1038/nature 10987

Fagg, A. H., Hatsopoulos, N. G., London, B. M., Reimer, J., Solla, S. A., Wang, D., et al. (2009). Toward a biomimetic, bidirectional, brain machine interface. Conf. Proc. IEEE Eng. Med. Biol. Soc. 2009, 3376-3380. doi: 10.1109/iembs.2009.5332819

Farwell, L. A., and Donchin, E. (1988). Talking off the top of your head: toward a mental prosthesis utilizing event-related brain potentials. Electroencephalogr. Clin. Neurophysiol. 70, 510-523. doi: 10.1016/0013-4694(88)90149-6

Favre, I., Zeffiro, T. A., Detante, O., Krainik, A., Hommel, M., and Jaillard, A. (2014). Upper limb recovery after stroke is associated with ipsilesional primary motor cortical activity: a meta-analysis. Stroke 45, 1077-1083. doi: 10.1161/STROKEAHA.113.003168

Feeney, D. M., and Baron, J. C. (1986). Diaschisis. Stroke 17, 817-830. doi: 10.1161/01.STR.17.5.817

Fishman, H. M., and Bittner, G. D. (2003). Vesicle-mediated restoration of a plasmalemmal barrier in severed axons. News Physiol. Sci. 18, 115-118. doi: 10.1152/nips.01429.2002

Fitzsimmons, N. A., Lebedev, M. A., Peikon, I. D., and Nicolelis, M. A. (2009). Extracting kinematic parameters for monkey bipedal walking from cortical neuronal ensemble activity. Front. Integr. Neurosci. 3:3. doi: 10.3389/neuro.07.003.2009

Flesher, S. N., Collinger, J. L., Foldes, S. T., Weiss, J. M., Downey, J. E., Tyler-Kabara, E. C., et al. (2016). Intracortical microstimulation of human somatosensory cortex. Sci. Transl. Med. 8:361ra141. doi: 10.1126/scitranslmed.aaf8083

Flint, R. D., Rosenow, J. M., Tate, M. C., and Slutzky, M. W. (2017). Continuous decoding of human grasp kinematics using epidural and subdural signals. $J$. Neural Eng. 14:016005. doi: 10.1088/1741-2560/14/1/016005

Flint, R. D., Scheid, M. R., Wright, Z. A., Solla, S. A., and Slutzky, M. W. (2016). Long-term stability of motor cortical activity: implications for brain machine interfaces and optimal feedback control. J. Neurosci. 36, 3623-3632. doi: 10.1523/JNEUROSCI.2339-15.2016

Flint, R. D., Wang, P. T., Wright, Z. A., King, C. E., Krucoff, M. O., Schuele, S. U., et al. (2014). Extracting kinetic information from human motor cortical signals. Neuroimage 101, 695-703. doi: 10.1016/j.neuroimage.2014.07.049

Flint, R. D., Wright, Z. A., Scheid, M. R., and Slutzky, M. W. (2013). Long term, stable brain machine interface performance using local field potentials and multiunit spikes. J. Neural Eng. 10:56005. doi: 10.1088/1741-2560/10/5/056005 
Flor, H., Elbert, T., Knecht, S., Wienbruch, C., Pantev, C., Birbaumer, N., et al. (1995). Phantom-limb pain as a perceptual correlate of cortical reorganization following arm amputation. Nature 375, 482-484. doi: 10.1038/375482a0

Fong, A. J., Roy, R. R., Ichiyama, R. M., Lavrov, I., Courtine, G., Gerasimenko, Y., et al. (2009). Recovery of control of posture and locomotion after a spinal cord injury: solutions staring us in the face. Prog. Brain Res. 175, 393-418. doi: 10.1016/S0079-6123(09)17526-X

Freund, P., Schmidlin, E., Wannier, T., Bloch, J., Mir, A., Schwab, M. E., et al. (2006). Nogo-A-specific antibody treatment enhances sprouting and functional recovery after cervical lesion in adult primates. Nat. Med. 12, 790-792. doi: $10.1038 / \mathrm{nm} 1436$

Friehs, G. M., Zerris, V. A., Ojakangas, C. L., Fellows, M. R., and Donoghue, J. P. (2004). Brain-machine and brain-computer interfaces. Stroke 35, 2702-2705. doi: 10.1161/01.STR.0000143235.93497.03

Furlanetti, L. L., Cordeiro, J. G., Cordeiro, K. K., García, J. A., Winkler, C., Lepski, G. A., et al. (2015). Continuous high-frequency stimulation of the subthalamic nucleus improves cell survival and functional recovery following dopaminergic cell transplantation in rodents. Neurorehabil. Neural Repair 29, 1001-1012. doi: $10.1177 / 1545968315581419$

Gad, P. N., Choe, J., Nandra, M. S., Zhong, H., Roy, R. R., Tai, Y.-C., et al. (2013a). Development of a multi-electrode array for spinal cord epidural stimulation to facilitate stepping and standing after a complete spinal cord injury in adult rats. J. Neuroeng. Rehabil. 10:2. doi: 10.1186/1743-0003-10-2

Gad, P. N., Choe, J., Shah, P., Garcia-Alias, G., Rath, M., Gerasimenko, Y., et al. (2013b). Sub-threshold spinal cord stimulation facilitates spontaneous motor activity in spinal rats. J. Neuroeng. Rehabil. 10:108. doi: 10.1186/1743-0003-10-108

Gad, P. N., Gerasimenko, Y. P., Zdunowski, S., Sayenko, D., Haakana, P., Turner, A., et al. (2015). Iron "ElectriRx" man: Overground stepping in an exoskeleton combined with noninvasive spinal cord stimulation after paralysis. Conf. Proc. IEEE Eng. Med. Biol. Soc. 2015, 1124-1127. doi: 10.1109/embc.2015.73 18563

Gad, P. N., Roy, R. R., Zhong, H., Lu, D. C., Gerasimenko, Y. P., and Edgerton, V. R. (2014). Initiation of bladder voiding with epidural stimulation in paralyzed, step trained rats. PLoS ONE 9:e108184. doi: 10.1371/journal.pone.0108184

García-Alías, G., Truong, K., Shah, P. K., Roy, R. R., and Edgerton, V. R. (2015). Plasticity of subcortical pathways promote recovery of skilled hand function in rats after corticospinal and rubrospinal tract injuries. Exp. Neurol. 266, 112-119. doi: 10.1016/j.expneurol.2015.01.009

Gerasimenko, Y., Gorodnichev, R., Moshonkina, T., Sayenko, D., Gad, P., and Reggie Edgerton, V. (2015a). Transcutaneous electrical spinalcord stimulation in humans. Ann. Phys. Rehabil. Med. 58, 225-231. doi: 10.1016/j.rehab.2015.05.003

Gerasimenko, Y., Lu, D., Modaber, M., Zdunowski, S., Gad, P., Sayenko, D., et al. (2015b). Noninvasive reactivation of motor descending control after paralysis. J. Neurotrauma 13, 1-13. doi: 10.1089/neu.2015.4008

Gharabaghi, A., Kraus, D., Leão, M. T., Spüler, M., Walter, A., Bogdan, M., et al. (2014a). Coupling brain-machine interfaces with cortical stimulation for brain-state dependent stimulation: enhancing motor cortex excitability for neurorehabilitation. Front. Hum. Neurosci. 8:122. doi: 10.3389/fnhum.2014.00122

Gharabaghi, A., Naros, G., Khademi, F., Jesser, J., Spüler, M., Walter, A., et al. (2014b). Learned self-regulation of the lesioned brain with epidural electrocorticography. Front. Behav. Neurosci. 8:429. doi: 10.3389/fnbeh.2014.00429

Gharabaghi, A., Naros, G., Walter, A., Grimm, F., Schuermeyer, M., Roth, A., et al. (2014c). From assistance towards restoration with epidural brain-computer interfacing. Restor. Neurol. Neurosci. 32, 517-525. doi: 10.3233/RNN-140387

Goforth, P. B., Ellis, E. F., and Satin, L. S. (1999). Enhancement of AMPA-mediated current after traumatic injury in cortical neurons. J. Neurosci. 19, 7367-7374.

Goldberg, J. L., Espinosa, J. S., Xu, Y., Davidson, N., Kovacs, G. T. A., and Barres, B. A. (2002). Retinal ganglion cells do not extend axons by default. Neuron 33, 689-702. doi: 10.1016/S0896-6273(02)00602-5

Grahn, P. J., Lee, K. H., Kasasbeh, A., Mallory, G. W., Hachmann, J. T., Dube, J. R., et al. (2015). Wireless control of intraspinal microstimulation in a rodent model of paralysis. J. Neurosci. 123, 232-242. doi: 10.3171/2014.10.jns132370

Greenberg, B. D., Malone, D. A., Friehs, G. M., Rezai, A. R., Kubu, C. S., Malloy, P. F., et al. (2006). Three-year outcomes in deep brain stimulation for highly resistant obsessive-compulsive disorder. Neuropsychopharmacology 31, 2384-2393. doi: 10.1038/sj.npp.1301165

Grenningloh, G., Soehrman, S., Bondallaz, P., Ruchti, E., and Cadas, H. (2004). Role of the microtubule destabilizing proteins SCG10 and stathmin in neuronal growth. J. Neurobiol. 58, 60-69. doi: 10.1002/neu.10279

Greve, M. W., and Zink, B. J. (2009). Pathophysiology of traumatic brain injury. Mt. Sinai J. Med. 76, 97-104. doi: 10.1002/msj.20104

Grillner, S. (1985). Neurobiological bases of rhythmic motor acts in vertebrates. Science 228, 143-149. doi: 10.1126/science.39 75635

Guggenmos, D. J., Azin, M., Barbay, S., Mahnken, J. D., Dunham, C., Mohseni, P., et al. (2013). Restoration of function after brain damage using a neural prosthesis. Proc. Natl. Acad. Sci. U.S.A. 110, 21177-21182. doi: $10.1073 /$ pnas. 1316885110

Hackett, M. L., Köhler, S., O'Brien, J. T., and Mead, G. E. (2014). Neuropsychiatric outcomes of stroke. Lancet Neurol. 13, 525-534. doi: 10.1016/S1474-4422(14)70016-X

Hamani, C., McAndrews, M. P., Cohn, M., Oh, M., Zumsteg, D., Shapiro, C. M., et al. (2008). Memory enhancement induced by hypothalamic/fornix deep brain stimulation. Ann. Neurol. 63, 119-123. doi: 10.1002/ana.21295

Hanson, T. L., Fuller, A. M., Lebedev, M. A., Turner, D. A., and Nicolelis, M. A. (2012). Subcortical neuronal ensembles: an analysis of motor task association, tremor, oscillations, and synchrony in human patients. J. Neurosci. 32, 8620-8632. doi: 10.1523/JNEUROSCI.0750-12.2012

Harkema, S. J., Gerasimenko, Y., Hodes, J., Burdick, J., Angeli, C., Chen, Y., et al. (2011). Effect of epidural stimulation of the lumbosacral spinal cord on voluntary movement, standing, and assisted stepping after motor complete paraplegia: a case study. Lancet 377, 1938-1947. doi: 10.1016/S0140-6736(11)60547-3

Harkema, S. J., Schmidt-Read, M., Lorenz, D. J., Edgerton, V. R., and Behrman, A. L. (2012). Balance and ambulation improvements in individuals with chronic incomplete spinal cord injury using locomotor trainingbased rehabilitation. Arch. Phys. Med. Rehabil. 93, 1508-1517. doi: 10.1016/j.apmr.2011. 01.024

Hasan, A., Nitsche, M. A., Rein, B., Schneider-Axmann, T., Guse, B., Gruber, O., et al. (2011). Dysfunctional long-term potentiation-like plasticity in schizophrenia revealed by transcranial direct current stimulation. Behav. Brain Res. 224, 15-22. doi: 10.1016/j.bbr.2011.05.017

Hatsopoulos, N. G., and Donoghue, J. P. (2009). The science of neural interface systems. Annu. Rev. Neurosci. 32, 249-266. doi: 10.1146/annurev.neuro.051508.135241

Hebb, D. O. (1949). The Organization of Behavior: A Neuropsychological Theory. New York, NY: Wiley.

Hergenroeder, G. W., Redell, J. B., Moore, A. N., and Dash, P. K. (2008). Biomarkers in the clinical diagnosis and management of traumatic brain injury. Mol. Diagn. Ther. 12, 345-358. doi: 10.1007/BF03256301

Hill, C. E., Beattie, M. S., and Bresnahan, J. C. (2001). Degeneration and sprouting of identified descending supraspinal axons after contusive spinal cord injury in the rat. Exp. Neurol. 171, 153-169. doi: 10.1006/exnr.2001.7734

Hochberg, L. R., Bacher, D., Jarosiewicz, B., Masse, N. Y., Simeral, J. D., Vogel, J., et al. (2012). Reach and grasp by people with tetraplegia using a neurally controlled robotic arm. Nature 485, 372-375. doi: 10.1038/nature11076

Hochberg, L. R., Serruya, M. D., Friehs, G. M., Mukand, J. A., Saleh, M., Caplan, A. H., et al. (2006). Neuronal ensemble control of prosthetic devices by a human with tetraplegia. Nature 442, 164-171. doi: 10.1038/nature04970

Hotson, G., McMullen, D. P., Fifer, M. S., Johannes, M. S., Katyal, K. D., Para, M. P., et al. (2016). Individual finger control of a modular prosthetic limb using high-density electrocorticography in a human subject. J. Neural Eng. 13:26017. doi: 10.1088/1741-2560/13/2/026017

Houeto, J. L., Karachi, C., Mallet, L., Pillon, B., Yelnik, J., Mesnage, V., et al. (2005). Tourette's syndrome and deep brain stimulation. J. Neurol. Neurosurg. Psychiatry 76, 992-995. doi: 10.1136/jnnp.2004.043273

Ifft, P. J., Shokur, S., Li, Z., Lebedev, M, A., and International, L. S. (2013). Brainmachine interface enables bimanual arm movements in monkeys. Sci. Transl. Med. 5:210ra154. doi: 10.1126/scitranslmed.3006159

Illis, L. S., Oygar, A. E., Sedgwick, E. M., and Awadalla, M. A. (1976). Dorsalcolumn stimulation in the rehabilitation of patients with multiple sclerosis. Lancet 307, 1383-1386. doi: 10.1016/S0140-6736(76)93030-0 
Ingram, J. N., Körding, K. P., Howard, I. S., and Wolpert, D. M. (2008). The statistics of natural hand movements. Exp. Brain Res. 188, 223-236. doi: $10.1007 / \mathrm{s} 00221-008-1355-3$

Iwahara, T., Atsuta, Y., Garcia-Rill, E., and Skinner, R. D. (1992). Spinal cord stimulation-induced locomotion in the adult cat. Brain Res. Bull. 28, 99-105. doi: 10.1016/0361-9230(92)90235-P

Jackson, A., and Zimmermann, J. B. (2012). Neural interfaces for the brain and spinal cord-restoring motor function. Nat. Rev. Neurol. 8, 690-699. doi: 10.1038/nrneurol.2012.219

Jarosiewicz, B., Bacher, D., Sarma, A. A., Masse, N. Y., Simeral, J. D., Sorice, B., et al. (2015). Virtual typing by people with tetraplegia using a stabilized, selfcalibrating intracortical brain-computer interface. Sci. Transl. Med. 7, 1-11. doi: $10.1126 /$ scitranslmed.aac7328

Jarvis, S., and Schultz, S. R. (2015). Prospects for optogenetic augmentation of brain function. Front. Syst. Neurosci. 9:157. doi: 10.3389/fnsys.2015.00157

Jennett, B., Teasdale, G., Braakman, R., Minderhoud, J., and Knill-Jones, R. (1976). Predicting outcome in individual patients after severe head injury. Lancet 15, 1031-1034. doi: 10.1016/S0140-6736(76)92215-7

Jones, L. (1997). Dextrous hands: human, prosthetic, and robotic. Presence 6, 29-56. doi: 10.1162/pres.1997.6.1.29

Jung, R., Belanger, A., Kanchiku, T., Fairchild, M., and Abbas, J. J. (2009). Neuromuscular stimulation therapy after incomplete spinal cord injury promotes recovery of interlimb coordination during locomotion. J. Neural Eng. 6:55010. doi: 10.1088/1741-2560/6/5/055010

Kafri, M., and Laufer, Y. (2015). Therapeutic effects of functional electrical stimulation on gait in individuals post-stroke. Ann. Biomed. Eng. 43, 451-466. doi: 10.1007/s10439-014-1148-8

Kantak, S. S., Stinear, J. W., Buch, E. R., and Cohen, L. G. (2012). Rewiring the brain: potential role of the premotor cortex in motor control, learning, and recovery of function following brain injury. Neurorehabil. Neural Repair 26, 282-292. doi: 10.1177/1545968311420845

Kennedy, P. R., and Bakay, R. A. (1998). Restoration of neural output from a paralyzed patient by a direct brain connection. Neuroreport 9, 1707-1711. doi: 10.1097/00001756-199806010-00007

Kern, H., McKay, W. B., Dimitrijevic, M. M., and Dimitrijevic, M. R. (2005). Motor control in the human spinal cord and the repair of cord function. Curr. Pharm. Des. 11, 1429-1439. doi: 10.2174/1381612053507882

Kim, D., Zai, L., Liang, P., Schaffling, C., Ahlborn, D., and Benowitz, L. I. (2013). Inosine enhances axon sprouting and motor recovery after spinal cord injury. PLoS ONE 8:e81948. doi: 10.1371/journal.pone.0081948

King, C. E., Wang, P. T., McCrimmon, C. M., Chou, C. C., Do, A. H., and Nenadic, Z. (2015). The feasibility of a brain-computer interface functional electrical stimulation system for the restoration of overground walking after paraplegia. J. Neuroeng. Rehabil. 12:80. doi: 10.1186/s12984-015-0068-7

Kleim, J. A., Bruneau, R., VandenBerg, P., MacDonald, E., Mulrooney, R., and Pocock, D. (2003). Motor cortex stimulation enhances motor recovery and reduces peri-infarct dysfunction following ischemic insult. Neurol. Res. 25, 789-793. doi: 10.1179/016164103771953862

Kleim, J. A., and Jones, T. A. (2008). Principles of experience-dependent neural plasticity: implications for rehabilitation after brain damage. J. Speech. Lang. Hear. Res. 51, S225-S239. doi: 10.1044/1092-4388(2008/018)

Kobayashi, M., and Pascual-Leone, A. (2003). Basic principles of magnetic stimulation. Lancet 2, 145-156. doi: 10.1016/S1474-4422(03)00321-1

Koch, C., Massimini, M., Boly, M., and Tononi, G. (2016). Neural correlates of consciousness: progress and problems. Nat. Rev. Neurosci. 17, 307-321. doi: $10.1038 /$ nrn.2016.22

Kozlowski, D. A., James, D. C., and Schallert, T. (1996). Use-dependent exaggeration of neuronal injury after unilateral sensorimotor cortex lesions. $J$. Neurosci. 16, 4776-4786.

Krieger, D. W. (2013). Therapeutic drug approach to stimulate clinical recovery after brain injury. Front. Neurol. Neurosci. 32:76-87. doi: 10.1159/000346419

Krucoff, M. O., and Slutzky, M. W. (2011). "Predicting grasp, kinetic, and kinematic variables of hand movement using epidural and subdural brain signals," in 63rd Annual Meeting of the American Academy of Neurology (Honolulu, $\mathrm{HI}$ ).

Krüger, J., Caruana, F., Volta, R. D., and Rizzolatti, G. (2010). Seven years of recording from monkey cortex with a chronically implanted multiple microelectrode. Front. Neuroeng. 3:6. doi: 10.3389/fneng.2010.00006
Kuner, R. (2010). Central mechanisms of pathological pain. Nat. Med. 16, 1258-1266. doi: 10.1038/nm.2231

Kurimoto, T., Yin, Y., Habboub, G., Gilbert, H.-Y., Li, Y., Nakao, S., et al. (2013). Neutrophils express oncomodulin and promote optic nerve regeneration. J. Neurosci. 33, 14816-14824. doi: 10.1523/JNEUROSCI.5511-12.2013

Kuznetsova, A. Y., and Deth, R. C. (2008). A model for modulation of neuronal synchronization by D4 dopamine receptor-mediated phospholipid methylation. J. Comput. Neurosci. 24, 314-329. doi: 10.1007/s10827-007-0057-3

Lang, C. E., Lohse, K. R., and Birkenmeier, R. L. (2015). Dose and timing in neurorehabilitation: prescribing motor therapy after stroke. Curr. Opin. Neurol. 28, 549-555. doi: 10.1097/WCO.0000000000000256

Langhorne, P., Bernhardt, J., and Kwakkel, G. (2011). Stroke rehabilitation. Lancet 377, 1693-1702. doi: 10.1016/S0140-6736(11)60325-5

Laxton, A. W., Lipsman, N., and Lozano, A. M. (2013). Deep brain stimulation for cognitive disorders. Handb. Clin. Neurol. 116, 307-311. doi: 10.1016/B978-0-444-53497-2.00025-5

Laxton, A. W., Tang-Wai, D. F., McAndrews, M. P., Zumsteg, D., Wennberg, R., Keren, R., et al. (2010). A phase I trial of deep brain stimulation of memory circuits in Alzheimer's disease. Ann. Neurol. 68, 521-534. doi: 10.1002/ana.22089

Laywell, E. D., Rakic, P., Kukekov, V. G., Holland, E. C., and Steindler, D. A. (2000). Identification of a multipotent astrocytic stem cell in the immature and adult mouse brain. Proc. Natl. Acad. Sci. U.S.A. 97, 13883-13888. doi: 10.1073/pnas.250471697

Lebedev, M. A., Tate, A. J., Hanson, T. L., Li, Z., O’Doherty, J. E., Winans, J. A., et al. (2011). Future developments in brain-machine interface research. Clinics 66, 25-32. doi: 10.1590/S1807-59322011001300004

Lee, J.-K., Kim, J.-E., Sivula, M., and Strittmatter, S. M. (2004). Nogo receptor antagonism promotes stroke recovery by enhancing axonal plasticity. $J$. Neurosci. 24, 6209-6217. doi: 10.1523/JNEUROSCI.1643-04.2004

Leuthardt, E. C., Schalk, G., Wolpaw, J. R., Ojemann, J. G., and Moran, D. W. (2004). A brain-computer interface using electrocorticographic signals in humans. J. Neural Eng. 1, 63-71. doi: 10.1088/1741-2560/1/2/001

Levy, R. M., Harvey, R. L., Kissela, B. M., Winstein, C. J., Lutsep, H. L., Parrish, T. B., et al. (2016). Epidural electrical stimulation for stroke rehabilitation: results of the prospective, multicenter, randomized, single-blinded everest trial. Neurorehabil. Neural Repair 30, 107-119. doi: 10.1177/1545968315 575613

Levy, R. M., Ruland, S., Weinand, M., Lowry, D., Dafer, R., and Bakay, R. (2008). Cortical stimulation for the rehabilitation of patients with hemiparetic stroke: a multicenter feasibility study of safety and efficacy. J. Neurosurg. 108, 707-714. doi: 10.3171/JNS/2008/108/4/0707

Li, S., Nie, E. H., Yin, Y., Benowitz, L. I., Tung, S., Vinters, H. V., et al. (2015). GDF10 is a signal for axonal sprouting and functional recovery after stroke. Nat. Neurosci. 18, 1737-1745. doi: 10.1038/nn.4146

Li, Y., and Raisman, G. (1995). Sprouts from cut corticospinal axons persist in the presence of astrocytic scarring in long-term lesions of the adult rat spinal cord. Exp. Neurol. 134, 102-111. doi: 10.1006/exnr.1995.1041

Liebscher, T., Schnell, L., Schnell, D., Scholl, J., Schneider, R., Gullo, M., et al. (2005). Nogo-A antibody improves regeneration and locomotion of spinal cord-injured rats. Ann. Neurol. 58, 706-719. doi: 10.1002/ana.20627

Liu, G., Gu, B., He, X. P., Joshi, R. B., Wackerle, H. D., Rodriguiz, R. M., et al. (2013). Transient inhibition of TrkB kinase after status epilepticus prevents development of temporal lobe epilepsy. Neuron 79, 31-38. doi: 10.1016/j.neuron.2013.04.027

Liu, K., Tedeschi, A., Park, K. K., and He, Z. (2011). Neuronal intrinsic mechanisms of axon regeneration. Annu. Rev. Neurosci. 34, 131-152. doi: 10.1146/annurev-neuro-061010-113723

Lloyd-Jones, D., Adams, R. J., Brown, T. M., Carnethon, M., Dai, S., De Simone, G., et al. (2010). Executive summary: heart disease and stroke statistics2010 update: a report from the american heart association. Circulation 121, e46-e215. doi: 10.1161/CIRCULATIONAHA.109.192667

Lo, A. C., Guarino, P. D., Richards, L. G., Haselkorn, J. K., Wittenberg, G. F., Federman, D. G., et al. (2010). Robot-assisted therapy for longterm upper-limb impairment after stroke. N. Engl. J. Med. 362, 1772-1783. doi: 10.1056/NEJMoa0911341

Lobel, D. A., and Lee, K. H. (2014). Brain machine interface and limb reanimation technologies: Restoring function after spinal cord injury 
through development of a bypass system. Mayo Clin. Proc. 89, 708-714. doi: 10.1016/j.mayocp.2014.02.003

London, B. M., Jordan, L. R., Jackson, C. R., and Miller, L. E. (2008). Electrical stimulation of the proprioceptive cortex (area 3a) used to instruct a behaving monkey. IEEE Trans. neural Syst. Rehabil. Eng. 16, 32-36. doi: 10.1109/TNSRE.2007.907544

Macas, J., Nern, C., Plate, K. H., and Momma, S. (2006). Increased generation of neuronal progenitors after ischemic injury in the aged adult human forebrain. J. Neurosci. 26, 13114-13119. doi: 10.1523/JNEUROSCI.4667-06.2006

Mackay-Lyons, M., McDonald, A., Matheson, J., Eskes, G., and Klus, M.-A. (2013). Dual effects of body-weight supported treadmill training on cardiovascular fitness and walking ability early after stroke: a randomized controlled trial. Neurorehabil. Neural Repair 27, 644-653. doi: 10.1177/1545968313484809

Magavi, S. S., Leavitt, B. R., and Macklis, J. D. (2000). Induction of neurogenesis in the neocortex of adult mice. Nature 405, 951-955. doi: 10.1038/35016083

Maier, I. C., Ichiyama, R. M., Courtine, G., Schnell, L., Lavrov, I., Edgerton, V. R., et al. (2009). Differential effects of anti-Nogo-A antibody treatment and treadmill training in rats with incomplete spinal cord injury. Brain 132, 1426-1440. doi: 10.1093/brain/awp085

Marmarou, A., Signoretti, S., Fatouros, P. P., Portella, G., Aygok, G. A., and Bullock, M. R. (2006). Predominance of cellular edema in traumatic brain swelling in patients with severe head injuries. J. Neurosurg. 104, 720-730. doi: 10.3171/jns.2006.104.5.720

Mayberg, H. S., Lozano, A. M., Voon, V., McNeely, H. E., Seminowicz, D., Hamani, C., et al. (2005). Deep brain stimulation for treatment-resistant depression. Neuron 45, 651-660. doi: 10.1016/j.neuron.2005.02.014

Mazurek, K. A., Holinski, B. J., Everaert, D. G., Mushahwar, V. K., and EtienneCummings, R. (2016). A mixed-signal VLSI system for producing temporally adapting intraspinal microstimulation patterns for locomotion. IEEE Trans. Biomed. Circuits Syst. 10, 902-911. doi: 10.1109/TBCAS.2015.2501419

McFarland, D. J., Krusienski, D. J., and Wolpaw, J. R. (2006). Brain-computer interface signal processing at the Wadsworth Center: mu and sensorimotor beta rhythms. Prog. Brain Res. 159, 411-419. doi: 10.1016/S0079-6123(06)59026-0

McFarland, D. J., Sarnacki, W. A., and Wolpaw, J. R. (2010). Electroencephalographic (EEG) control of three-dimensional movement. J. Neural Eng. 7:36007. doi: 10.1088/1741-2560/7/3/036007

McGee, M. J., Amundsen, C. L., and Grill, W. M. (2015). Electrical stimulation for the treatment of lower urinary tract dysfunction after spinal cord injury. J. Spinal Cord Med. 38, 135-146. doi: 10.1179/2045772314Y.00000 00299

McGee, M. J., and Grill, W. M. (2014). Selective co-stimulation of pudendal afferents enhances bladder activation and improves voiding efficiency. Neurourol. Urodyn. 33, 1272-1278. doi: 10.1002/nau.22474

McIntyre, A., Viana, R., Janzen, S., Mehta, S., Pereira, S., and Teasell, R. (2012). Systematic review and meta-analysis of constraint-induced movement therapy in the hemiparetic upper extremity more than six months post stroke. Top. Stroke Rehabil. 19, 499-513. doi: 10.1310/tsr1906-499

Memberg, W. D., Polasek, K. H., Hart, R. L., Bryden, A. M., Kilgore, K. L., Nemunaitis, G. A., et al. (2014). Implanted neuroprosthesis for restoring arm and hand function in people with high level tetraplegia. Arch. Phys. Med. Rehabil. 95, 1201-1211.e1. doi: 10.1016/j.apmr.2014.01.028

Menzer, D. L., Rao, N. G., Bondy, A., Truccolo, W., and Donoghue, J. P. (2014). Population interactions between parietal and primary motor cortices during reach. J. Neurophysiol. 112, 2959-2984. doi: 10.1152/jn.00851.2012

Mestais, C. S., Charvet, G., Sauter-starace, F., Foerster, M., and Ratel, D. (2015). WIMAGINE: wireless 64-channel ECoG recording implant for long term clinical applications. IEEE Trans. Neural Syst. Rehabil. Eng. 23, 10-21. doi: 10.1109/TNSRE.2014.2333541

Meunier, D., Lambiotte, R., and Bullmore, E. T. (2010). Modular and hierarchically modular organization of brain networks. Front. Neurosci. 4:200. doi: 10.3389/ fnins.2010.00200

Mihara, M., Hattori, N., Hatakenaka, M., Yagura, H., Kawano, T., Hino, T., et al. (2013). Near-infrared spectroscopy-mediated neurofeedback enhances efficacy of motor imagery-based training in poststroke victims: a pilot study. Stroke 44, 1091-1098. doi: 10.1161/STROKEAHA.111.674507

Milot, M.-H., Spencer, S. J., Chan, V., Allington, J. P., Klein, J., Chou, C., et al. (2013). A crossover pilot study evaluating the functional outcomes of two different types of robotic movement training in chronic stroke survivors using the arm exoskeleton BONES. J. Neuroeng. Rehabil. 10:112. doi: 10.1186/1743-0003-10-112

Minassian, K., Jilge, B., Rattay, F., Pinter, M. M., Binder, H., Gerstenbrand, F., et al. (2004). Stepping-like movements in humans with complete spinal cord injury induced by epidural stimulation of the lumbar cord: electromyographic study of compound muscle action potentials. Spinal Cord 42, 401-416. doi: $10.1038 /$ sj.sc.3101615

Minassian, K., Persy, I., Rattay, F., Pinter, M. M., Kern, H., and Dimitrijevic, M. R. (2007). Human lumbar cord circuitries can be activated by extrinsic tonic input to generate locomotor-like activity. Hum. Mov. Sci. 26, 275-295. doi: 10.1016/j.humov.2007.01.005

Minev, I. R., Musienko, P., Hirsch, A., Barraud, Q., Wenger, N., Moraud, E. M., et al. (2015). Electronic dura mater for long term multimodal neural interfaces. Science 347, 159-163. doi: 10.1126/science. 1260318

Monfils, M.-H., VandenBerg, P. M., Kleim, J. A., and Teskey, G. C. (2004). Longterm potentiation induces expanded movement representations and dendritic hypertrophy in layer $\mathrm{V}$ of rat sensorimotor neocortex. Cereb. Cortex 14, 586-593. doi: 10.1093/cercor/bhh020

Moritz, C. T., Perlmutter, S. I., and Fetz, E. E. (2008). Direct control of paralysed muscles by cortical neurons. Nature 456, 639-642. doi: 10.1038/nature07418

Morrow, M. M., Jordan, L. R., and Miller, L. E. (2007). Direct comparison of the task-dependent discharge of M1 in hand space and muscle space. $J$. Neurophysiol. 97, 1786-1798. doi: 10.1152/jn.00150.2006

Mothe, A. J., and Tator, C. H. (2012). Advances in stem cell therapy for spinal cord injury. Thew J. Clin. Investig. 122, 3824-3834. doi: 10.1172/JCI64124

Nahmani, M., and Turrigiano, G. G. (2014). Adult cortical plasticity following injury: recapitulation of critical period mechanisms? Neuroscience 283, 4-16. doi: 10.1016/j.neuroscience.2014.04.029

Napieralski, J. A., Butler, A. K., and Chesselet, M. F. (1996). Anatomical and functional evidence for lesion-specific sprouting of corticostriatal input in the adult rat. J. Comp. Neurol. 373, 484-497.

Nicolelis, M. A., and Lebedev, M. A. (2009). Principles of neural ensemble physiology underlying the operation of brain-machine interfaces. Nat. Rev. Neurosci. 10, 530-540. doi: 10.1038/nrn2653

Nudo, R. J. (2013). Recovery after brain injury: mechanisms and principles. Front. Hum. Neurosci. 7:887. doi: 10.3389/fnhum.2013.00887

Nudo, R. J., Jenkins, W. M., and Merzenich, M. M. (1990). Repetitive microstimulation alters the cortical representation of movements in adult rats. Somatosens. Mot. Res. 7, 463-483. doi: 10.3109/08990229009144720

Nudo, R. J., and Milliken, G. W. (1996). Reorganization of movement representations in primary motor cortex following focal ischemic infarcts in adult squirrel monkeys. J. Neurophysiol. 75, 2144-2149.

Nuyujukian, B. P., Ieee, M., Kao, J. C., Ieee, S. M., Ryu, S. I., Ieee, M., et al. (2016). Brain - computer typing Interface. Proc. IEEE 1-7. doi: 10.1109/JPROC.2016.2586967

O’Doherty, J. E., Lebedev, M. A., Hanson, T. L., Fitzsimmons, N. A., and Nicolelis, M. A. L. (2009). A brain-machine interface instructed by direct intracortical microstimulation. Front. Integr. Neurosci. 3:20. doi: 10.3389/neuro.07.020.2009

Ohab, J. J., and Carmichael, S. T. (2008). Poststroke neurogenesis: emerging principles of migration and localization of immature neurons. Neuroscience 14, 369-380. doi: 10.1177/1073858407309545

Omura, T., Omura, K., Tedeschi, A., Riva, P., Painter, M. W., Rojas, L., et al. (2015). Robust axonal regeneration occurs in the injured CAST/Ei mouse CNS. Neuron 86, 1215-1227. doi: 10.1016/j.neuron.2015.05.005

Oxley, T. J., Opie, N. L., John, S. E., Rind, G. S., Ronayne, S. M., Wheeler, T. L., et al. (2016). Minimally invasive endovascular stent-electrode array for high-fidelity, chronic recordings of cortical neural activity. Nat. Biotechnol. 34, 320-327. doi: $10.1038 /$ nbt. 3428

Pais-Vieira, M., Chiuffa, G., Lebedev, M., Yadav, A., and Nicolelis, M. A. L. (2015). Building an organic computing device with multiple interconnected brains. Sci. Rep. 5:11869. doi: 10.1038/srep11869

Park, C. K., Nehls, D. G., Teasdale, G. M., and McCulloch, J. (1989). Effect of the NMDA antagonist MK-801 on local cerebral blood flow in focal cerebral ischaemia in the rat. J. Cereb. Blood Flow Metab. 9, 617-622. doi: $10.1038 /$ jcbfm.1989.88

Park, K. K., Liu, K., Hu, Y., Smith, P. D., Wang, C., Cai, B., et al. (2008). Promoting axon regeneration in the adult CNS by modulation of the PTEN/mTOR pathway. Science 322, 963-966. doi: 10.1126/science.1161566 
Patil, P. G., Carmena, J. M., Nicolelis, M. A., and Turner, D. A. (2004). Ensemble recordings of human subcortical neurons as a source of motor control signals for a brain-machine interface. Neurosurgery 55, 27-35. doi: 10.1227/01.neu.0000126872.23715.e5

Patil, P. G., and Turner, D. A. (2008). The development of brainmachine interface neuroprosthetic devices. Neurotherapeutics 5, 137-146. doi: 10.1016/j.nurt.2007.11.002

Pekna, M., Pekny, M., and Nilsson, M. (2012). Modulation of neural plasticity as a basis for stroke rehabilitation. Stroke 43, 2819-2828. doi: 10.1161/STROKEAHA.112.654228

Perel, P., Arango, M., Clayton, T., Edwards, P., Komolafe, E., Poccock, S., et al. (2008). Predicting outcome after traumatic brain injury: practical prognostic models based on large cohort of international patients. BMJ 336, 425-429. doi: 10.1136/bmj.39461.643438.25

Pfurtscheller, G., Brunner, C., Schlögl, A., and Lopes da Silva, F. H. (2006). Mu rhythm (de)synchronization and EEG single-trial classification of different motor imagery tasks. Neuroimage 31, 153-159. doi: 10.1016/j.neuroimage.2005.12.003

Pfurtscheller, G., Flotzinger, D., Mohl, W., and Peltoranta, M. (1992). Prediction of the side of hand movements from single-trial multi-channel EEG data using neural networks. Electroencephalogr. Clin. Neurophysiol. 82, 313-315. doi: 10.1016/0013-4694(92)90112-U

Plautz, E. J., Barbay, S., Frost, S. B., Friel, K. M., Dancause, N., Zoubina, E. V., et al. (2003). Post-infarct cortical plasticity and behavioral recovery using concurrent cortical stimulation and rehabilitative training: a feasibility study in primates. Neurol. Res. 25, 801-810. doi: 10.1179/016164103771953880

Popovic, M. R., Kapadia, N., Zivanovic, V., Furlan, J. C., Craven, B. C., and McGillivray, C. (2011). Functional electrical stimulation therapy of voluntary grasping versus only conventional rehabilitation for patients with subacute incomplete tetraplegia: a randomized clinical trial. Neurorehabil. Neural Repair 25, 433-442. doi: 10.1177/1545968310392924

Prochazka, A. (2016). Targeted stimulation of the spinal cord to restore locomotor activity. Nat. Med. 22, 125-126. doi: 10.1038/nm.4043

Protas, E. J., Holmes, S. A., Qureshy, H., Johnson, A., Lee, D., and Sherwood, A. M. (2001). Supported treadmill ambulation training after spinal cord injury: a pilot study. Arch. Phys. Med. Rehabil. 82, 825-831. doi: 10.1053/apmr.2001.23198

Quartarone, A., Rizzo, V., and Morgante, F. (2008). Clinical features of dystonia: a pathophysiological revisitation. Curr. Opin. Neurol. 21, 484-490. doi: 10.1097/WCO.0b013e328307bf07

Rajangam, S., Tseng, P.-H., Yin, A., Lehew, G., Schwarz, D., Lebedev, M. A., et al. (2016). Wireless cortical brain-machine interface for whole-body navigation in primates. Sci. Rep. 6:22170. doi: 10.1038/srep22170

Ramakrishnan, A., Ifft, P. J., Pais-Vieira, M., Byun, Y. W., Zhuang, K. Z., Lebedev, M. A., et al. (2015). Computing arm movements with a monkey brainet. Sci. Rep. 5:10767. doi: 10.1038/srep10767

Ramos-Murguialday, A., Broetz, D., Rea, M., Läer, L., Yilmaz, O., Brasil, F. L., et al. (2013). Brain-machine interface in chronic stroke rehabilitation: a controlled study. Ann. Neurol. 74, 100-108. doi: 10.1002/ana.23879

Ramos-Murguialday, A., Schürholz, M., Caggiano, V., Wildgruber, M., Caria, A., Hammer, E. M., et al. (2012). Proprioceptive feedback and brain computer interface (BCI) based neuroprostheses. PLoS ONE 7:e47048. doi: 10.1371/journal.pone.0047048

Rattay, F., Minassian, K., and Dimitrijevic, M. R. (2000). Epidural electrical stimulation of posterior structures of the human lumbosacral cord: 2 . quantitative analysis by computer modeling. Spinal Cord 38, 473-489. doi: $10.1038 /$ sj.sc.3101039

Rea, M., Rana, M., Lugato, N., Terekhin, P., Gizzi, L., Brötz, D., et al. (2014). Lower limb movement preparation in chronic stroke: a pilot study toward an fNIRS-BCI for gait rehabilitation. Neurorehabil. Neural Repair 28, 564-575. doi: $10.1177 / 1545968313520410$

Rebesco, J. M., and Miller, L. E. (2011). Enhanced detection threshold for in vivo cortical stimulation produced by Hebbian conditioning. J. Neural Eng. 8:16011. doi: 10.1088/1741-2560/8/1/016011

Reinkensmeyer, D. J., Aoyagi, D., Emken, J. L., Galvez, J. A., Ichinose, W., Kerdanyan, G., et al. (2006). Tools for understanding and optimizing robotic gait training. J. Rehabil. Res. Dev. 43, 657-670. doi: 10.1682/JRRD.2005.04.0073
Reinkensmeyer, D. J., Emken, J. L., and Cramer, S. C. (2004). Robotics, motor learning, and neurologic recovery. Annu. Rev. Biomed. Eng. 6, 497-525. doi: 10.1146/annurev.bioeng.6.040803.140223

Rigosa, J., Panarese, A., Dominici, N., Friedli, L., van den Brand, R., Carpaneto, J., et al. (2015). Decoding bipedal locomotion from the rat sensorimotor cortex. J. Neural Eng. 12:56014. doi: 10.1088/1741-2560/12/5/056014

Roy, R. R., Harkema, S. J., and Edgerton, V. R. (2012). Basic concepts of activity-based interventions for improved recovery of motor function after spinal cord injury. Arch. Phys. Med. Rehabil. 93, 1487-1497. doi: 10.1016/j.apmr.2012.04.034

Ryapolova-Webb, E., Afshar, P., Stanslaski, S., Denison, T., de Hemptinne, C., Bankiewicz, K., et al. (2014). Chronic cortical and electromyographic recordings from a fully implantable device: preclinical experience in a nonhuman primate. J. Neural Eng. 11:16009. doi: 10.1088/1741-2560/11/1/016009

Sakurada, T., Kawase, T., Takano, K., Komatsu, T., and Kansaku, K. (2013). A BMIbased occupational therapy assist suit: asynchronous control by SSVEP. Front. Neurosci. 7:172. doi: 10.3389/fnins.2013.00172

Sandberg, K., Frässle, S., and Pitts, M. (2016). Future directions for identifying the neural correlates of consciousness. Nat. Rev. Neurosci. doi: 10.1038/nrn.2016.104. [Epub ahead of print].

Sayenko, D. G., Angeli, C., Harkema, S. J., Edgerton, V. R., and Gerasimenko, Y. P. (2014). Neuromodulation of evoked muscle potentials induced by epidural spinal-cord stimulation in paralyzed individuals. J. Neurophysiol. 111, 1088-1099. doi: 10.1152/jn.00489.2013

Schaechter, J. D., Moore, C. I., Connell, B. D., Rosen, B. R., and Dijkhuizen, R. M. (2006). Structural and functional plasticity in the somatosensory cortex of chronic stroke patients. Brain 129, 2722-2733. doi: 10.1093/brain/awl214

Schlaepfer, W. W., and Bunge, R. P. (1973). Effects of calcium ion concentration on the degeneration of amputated axons in tissue culture. J. Cell Biol. 59, 456-470. doi: $10.1083 /$ jcb.59.2.456

Schwarz, D. A., Lebedev, M. A., Hanson, T. L., Dimitrov, D. F., Lehew, G., Meloy, J., et al. (2014). Chronic, wireless recordings of large-scale brain activity in freely moving rhesus monkeys. Nat. Methods 11, 670-676. doi: 10.1038/nmeth.2936

Serences, J. T., and Yantis, S. (2006). Selective visual attention and perceptual coherence. Trends Cogn. Sci. 10, 38-45. doi: 10.1016/j.tics.2005.11.008

Seri, B., García-Verdugo, J. M., McEwen, B. S., and Alvarez-Buylla, A. (2001). Astrocytes give rise to new neurons in the adult mammalian hippocampus. $J$. Neurosci. 21, 7153-7160.

Sherwood, A. M., Dimitrijevic, M. R., and Barry McKay, W. (1992). Evidence of subclinical brain influence in clinically complete spinal cord injury: discomplete SCI. J. Neurol Sci. 110, 90-98. doi: 10.1016/0022-510X(92)90014-C

Shetty, A. K., and Turner, D. A. (1995). Enhanced cell survival in fetal hippocampal suspension transplants grafted to adult rat hippocampus following kainate lesions: a three-dimensional graft reconstruction study. Neuroscience 67, 561-582. doi: 10.1016/0306-4522(95)00025-E

Shetty, A. K., and Turner, D. A. (1999). Aging impairs axonal sprouting response of dentate granule cells following target loss and partial deafferentation. J. Comp. Neurol. 414, 238-254.

Shetty, P. K., Galeffi, F., and Turner, D. A. (2014). Nicotinamide pre-treatment ameliorates $\mathrm{NAD}(\mathrm{H})$ hyperoxidation and improves neuronal function after severe hypoxia. Neurobiol. Dis. 62, 469-478. doi: 10.1016/j.nbd.2013.10.025

Shik, M. L., and Orlovsky, G. N. (1976). Neurophysiology of locomotor automatism. Physiol. Rev. 56, 465-501.

Shin, S., Dixon, E., Okonkwo, D., and Richardson, M. (2014). Neurostimulation for traumatic brain injury. J. Neurosurg. 121, 1219-1231. doi: 10.3171/2014.7.JNS131826

Sitaram, R., Caria, A., and Birbaumer, N. (2009). Hemodynamic brain-computer interfaces for communication and rehabilitation. Neural Netw. 22, 1320-1328. doi: 10.1016/j.neunet.2009.05.009

Smith, P. D., Sun, F., Park, K. K., Cai, B., Wang, C., Kuwako, K., et al. (2009). SOCS3 deletion promotes optic nerve regeneration in vivo. Neuron 64, 617-623. doi: 10.1016/j.neuron.2009.11.021

Soekadar, S. R., Birbaumer, N., Slutzky, M. W., and Cohen, L. G. (2015). Brain-machine interfaces in neurorehabilitation of stroke. Neurobiol. Dis. 83, 172-179. doi: 10.1016/j.nbd.2014.11.025 
Stefan, K., Kunesch, E., Cohen, L. G., Benecke, R., and Classen, J. (2000). Induction of plasticity in the human motor cortex by paired associative stimulation. Brain 123(Pt 3), 572-584. doi: 10.1093/brain/123.3.572

Stevenson, I. H., London, B. M., Oby, E. R., Sachs, N. A., Reimer, J., Englitz, B., et al. (2012). Functional connectivity and tuning curves in populations of simultaneously recorded neurons. PLoS Comput. Biol. 8:e1002775. doi: 10.1371/journal.pcbi.1002775

Steyerberg, E. W., Mushkudiani, N., Perel, P., Butcher, I., Lu, J., McHugh, G. S., et al. (2008). Predicting outcome after traumatic brain injury: development and international validation of prognostic scores based on admission characteristics. PLoS Med. 5:e165. doi: 10.1371/journal.pmed.0050165

Stockwell, R. A. (1981). “Joints," in Cunningham's Textbook of Anatomy, ed G. J. Romanes (Oxford: Oxford Medical Publications), 211-264.

Stroemer, R. P., Kent, T. A., and Hulsebosch, C. E. (1995). Neocortical neural sprouting, synaptogenesis, and behavioral recovery after neocortical infarction in rats. Stroke 26, 2135-2144. doi: 10.1161/01.STR.26.11.2135

Suh, S. W., Chen, J. W., Motamedi, M., Bell, B., Listiak, K., Pons, N. F., et al. (2000). Evidence that synaptically-released zinc contributes to neuronal injury after traumatic brain injury. Brain Res. 852, 268-273. doi: 10.1016/S0006-8993(99)02095-8

Sun, F., and He, Z. (2010). Neuronal intrinsic barriers for axon regeneration in the adult CNS. Curr. Opin. Neurobiol. 20, 510-518. doi: 10.1016/j.conb.2010.03.013

Suthana, N., Haneef, Z., Stern, J., Mukamel, R., Behnke, E., Knowlton, B., et al. (2012). Memory enhancement and deep-brain stimulation of the entorhinal area. N. Engl. J. Med. 366, 502-510. doi: 10.1056/NEJMoa1107212

Sweet, J. A., Eakin, K. C., Munyon, C. N., and Miller, J. P. (2014). Improved learning and memory with theta-burst stimulation of the fornix in rat model of traumatic brain injury. Hippocampus 24, 1592-1600. doi: 10.1002/hipo.22338

Tator, C. H. (1995). Update on the pathophysiology and pathology of acute spinal cord injury. Brain Pathol. 5, 407-413. doi: 10.1111/j.1750-3639.1995.tb00619.x

Tator, C. H., and Edmonds, V. E. (1979). Acute spinal cord injury: analysis of epidemiologic factors. Can. J. Surg. 22, 575-578.

Tator, C. H., and Fehlings, M. G. (1991). Review of the secondary injury theory of acute spinal cord trauma with emphasis on vascular mechanisms. J. Neurosurg. 75, 15-26. doi: 10.3171/jns.1991.75.1.0015

Taub, E., and Morris, D. M. (2001). Constraint-induced movement therapy to enhance recovery after stroke. Curr. Atheroscler. Rep. 3, 279-286. doi: 10.1007/s11883-001-0020-0

Taub, E., Uswatte, G., and Elbert, T. (2002). New treatments in neurorehabilitation founded on basic research. Nat. Rev. Neurosci. 3, 228-236. doi: 10.1038/nrn754

Teasell, R. W., Murie Fernandez, M., McIntyre, A., and Mehta, S. (2014). Rethinking the continuum of stroke rehabilitation. Arch. Phys. Med. Rehabil. 95, 595-596. doi: 10.1016/j.apmr.2013.11.014

Tedeschi, A. (2011). Tuning the orchestra: transcriptional pathways controlling axon regeneration. Front. Mol. Neurosci. 4:60. doi: 10.3389/fnmol.2011.00060

Terroni, L., Amaro, E., Iosifescu, D. V., Tinone, G., Sato, J. R., Leite, C. C., et al. (2011). Stroke lesion in cortical neural circuits and post-stroke incidence of major depressive episode: a 4-month prospective study. World J. Biol. Psychiatry 12, 539-548. doi: 10.3109/15622975.2011.562242

Teyler, T. J., Morgan, S. L., Russell, R. N., and Woodside, B. L. (2001). Synaptic plasticity and secondary epileptogenesis. Int. Rev. Neurobiol. 45, 253-267. doi: 10.1016/S0074-7742(01)45014-8

Thickbroom, G. W., and Mastaglia, F. L. (2009). Plasticity in neurological disorders and challenges for noninvasive brain stimulation (NBS). J. Neuroeng. Rehabil. 6:4. doi: 10.1186/1743-0003-6-4

Thompson, K., Pohlmann-Eden, B., Campbell, L. A., and Abel, H. (2015). Pharmacological treatments for preventing epilepsy following traumatic head injury. Cochrane Database Syst. Rev. 8:CD009900. doi: 10.1002/14651858.CD009900.pub2

Thored, P., Arvidsson, A., Cacci, E., Ahlenius, H., Kallur, T., Darsalia, V., et al. (2006). Persistent production of neurons from adult brain stem cells during recovery after stroke. Stem Cells 24, 739-747. doi: 10.1634/stemcells.2005-0281

Troyk, P. R., Mushahwar, V. K., Stein, R. B., Suh, S., Everaert, D., Holinski, B., et al. (2012). An implantable neural stimulator for intraspinal microstimulation. Conf. Proc. IEEE Eng. Med. Biol. Soc. 2012, 900-903. doi: 10.1109/embc.2012.6346077

Turner, D. A., Patil, P. G., and Nicolelis, M. A. L. (2008). "Conceptual and technical approaches to human neural ensemble recordings," in Methods Neural
Ensemble Rec. 2nd Edn., ed M. A. L. Nicolelis (Boca Raton, FL: CRC Press; Taylor \& Francis), 1-17.

van den Brand, R., Heutschi, J., Barraud, Q., DiGiovanna, J., Bartholdi, K., Huerlimann, M., et al. (2012). Restoring voluntary control of locomotion after paralyzing spinal cord injury. Science 336, 1182-1185. doi: $10.1126 /$ science.1217416

van den Brand, R., Mignardot, J. B., von Zitzewitz, J., Le Goff, C., Fumeaux, N., Wagner, F., et al. (2015). Neuroprosthetic technologies to augment the impact of neurorehabilitation after spinal cord injury. Ann. Phys. Rehabil. Med. 58, 232-237. doi: 10.1016/j.rehab.2015.04.003

Vansteensel, M. J., Pels, E. G. M., Bleichner, M. G., Branco, M. P., Denison, T., Freudenburg, Z. V., et al. (2016). Fully implanted brain-computer interface in a locked-in patient with ALS. N. Engl. J. Med. 375, 2060-2066. doi: 10.1056/nejmoal6 08085

Vargas-Irwin, C. E., Shakhnarovich, G., Yadollahpour, P., Mislow, J. M. K., Black, M. J., and Donoghue, J. P. (2010). Decoding complete reach and grasp actions from local primary motor cortex populations. J. Neurosci. 30, 9659-9669. doi: 10.1523/JNEUROSCI.5443-09.2010

Vidaurre, C., Klauer, C., Schauer, T., Ramos-Murguialday, A., and Müller, K.-R. (2016). EEG-based BCI for the linear control of an upper-limb neuroprosthesis. Med. Eng. Phys. 38, 1195-1204. doi: 10.1016/j.medengphy.2016.06.010

Villamar, M. F., Santos Portilla, A., Fregni, F., and Zafonte, R. (2012). Noninvasive brain stimulation to modulate neuroplasticity in traumatic brain injury. Neuromodulation 15, 326-337. doi: 10.1111/j.1525-1403.2012. 00474.x

Wahl, A. S., Omlor, W., Rubio, J. C., Chen, J. L., Zheng, H., Schröter, A., et al. (2014). Asynchronous therapy restores motor control by rewiring of the rat corticospinal tract after stroke. Science 344, 1250-1255. doi: 10.1126/science. 1253050

Warren Olanow, C., Bartus, R. T., Baumann, T. L., Factor, S., Boulis, N., Stacy, M., et al. (2015). Gene delivery of neurturin to putamen and substantia nigra in Parkinson disease: a double-blind, randomized, controlled trial. Ann. Neurol. 78, 248-257. doi: 10.1002/ana.24436

Waters, R. L., Adkins, R. H., Yakura, J. S., and Sie, I. (1996). Effect of surgery on motor recovery following traumatic spinal cord injury. Spinal Cord 34, 188-192. doi: 10.1038/sc.1996.37

Waters, R. L., Yakura, J. S., Adkins, R. H., and Sie, I. (1992). Recovery following complete paraplegia. Arch. Phys. Med. Rehabil. 73, 784-789.

Weiskopf, N., Veit, R., Erb, M., Mathiak, K., Grodd, W., Goebel, R., et al. (2003). Physiological self-regulation of regional brain activity using real-time functional magnetic resonance imaging (fMRI): methodology and exemplary data. Neuroimage 19, 577-586. doi: 10.1016/S1053-8119(03)00145-9

Wernig, A., and Müller, S. (1992). Laufband locomotion with body weight support improved walking in persons with severe spinal cord injuries. Paraplegia 30, 229-238. doi: 10.1038/sc.1992.61

Wernig, A., Nanassy, A., and Müller, S. (1998). Maintenance of locomotor abilities following Laufband (treadmill) therapy in para- and tetraplegic persons: followup studies. Spinal Cord 36, 744-749. doi: 10.1038/sj.sc.3100670

Wessberg, J., Stambaugh, C. R., Kralik, J. D., Beck, P. D., Laubach, M., Chapin, J. K., et al. (2000). Real-time prediction of hand trajectory by ensembles of cortical neurons in primates. Nature 408, 361-365. doi: 10.1038/350 42582

Wolf, S. L., Winstein, C. J., Miller, J. P., Taub, E., Uswatte, G., Morris, D., et al. (2006). Effect of constraint-induced movement therapy on upper extremity function 3 to 9 months after stroke: the EXCITE randomized clinical trial. JAMA 296, 2095-2104. doi: 10.1001/jama.296.17.2095

Wolman, L. (1965). The disturbance of circulation in traumatic paraplegia in acute and late stages: a pathological study. Paraplegia 2, 213-226. doi: $10.1038 /$ sc. 1964.39

Wolpaw, J. R., and McFarland, D. J. (1994). Multichannel EEG-based braincomputer communication. Electroencephalogr. Clin. Neurophysiol. 90, 444-449. doi: 10.1016/0013-4694(94)90135-X

Wolpaw, J. R., and Tennissen, A. M. (2001). Activity-dependent spinal cord plasticity in health and disease. Annu. Rev. Neurosci. 24, 807-843. doi: 10.1146/annurev.neuro.24.1.807

Womelsdorf, T., Schoffelen, J.-M., Oostenveld, R., Singer, W., Desimone, R., Engel, A. K., et al. (2007). Modulation of neuronal interactions through 
neuronal synchronization. Science 316, 1609-1612. doi: 10.1126/science.11 39597

Xi, G., Keep, R., and Hoff, J. (2006). Mechanisms of brain injury after intracerebral haemorrhage. Lancet Neurol. 5, 53-63. doi: 10.1016/S1474-4422(05)70 283-0

Yin, Y., Cui, Q., Gilbert, H.-Y., Yang, Y., Yang, Z., Berlinicke, C., et al. (2009). Oncomodulin links inflammation to optic nerve regeneration. Proc. Natl. Acad. Sci. U.S.A. 106, 19587-19592. doi: 10.1073/pnas.0907085106

Yin, Y., Cui, Q., Li, Y., Irwin, N., Fischer, D., Harvey, A. R., et al. (2003). Macrophage-derived factors stimulate optic nerve regeneration. J. Neurosci. 23, 2284-2293.

Yin, Y., Henzl, M. T., Lorber, B., Nakazawa, T., Thomas, T. T., Jiang, F., et al. (2006). Oncomodulin is a macrophage-derived signal for axon regeneration in retinal ganglion cells. Nat. Neurosci. 9, 843-852. doi: 10.1038/ nn1701

Yurkewicz, L., Weaver, J., Bullock, M. R., and Marshall, L. L. (2005). The effect of the selective NMDA receptor antagonist traxoprodil in the treatment of traumatic brain injury. J. Neurotrauma 22, 1428-1443. doi: 10.1089/neu.2005.22.1428

Zai, L., Ferrari, C., Dice, C., Subbaiah, S., Havton, L. A., Coppola, G., et al. (2011). Inosine augments the effects of a Nogo receptor blocker and of environmental enrichment to restore skilled forelimb use after stroke. J. Neurosci. 31, 5977-5988. doi: 10.1523/JNEUROSCI.449810.2011

Zai, L., Ferrari, C., Subbaiah, S., Havton, L. A., Coppola, G., Strittmatter, S., et al. (2009). Inosine alters gene expression and axonal projections in neurons contralateral to a cortical infarct and improves skilled use of the impaired limb. J. Neurosci. 29, 8187-8197. doi: 10.1523/JNEUROSCI.041409.2009
Zetterberg, H., Smith, D. H., and Blennow, K. (2013). Biomarkers of mild traumatic brain injury in cerebrospinal fluid and blood. Nat. Rev. Neurol. 9, 201-210. doi: 10.1038/nrneurol.2013.9

Zhang, R. L., Zhang, Z. G., Zhang, L., and Chopp, M. (2001). Proliferation and differentiation of progenitor cells in the cortex and the subventricular zone in the adult rat after focal cerebral ischemia. Neuroscience 105, 33-41. doi: 10.1016/S0306-4522(01)00117-8

Zimmermann, J. B., and Jackson, A. (2014). Closed-loop control of spinal cord stimulation to restore hand function after paralysis. Front. Neurosci. 8:87. doi: 10.3389/fnins.2014.00087

Zink, B. J., Szmydynger-Chodobska, J., and Chodobski, A. (2010). Emerging concepts in the pathophysiology of traumatic brain injury. Psychiatr. Clin. North Am. 33, 741-756. doi: 10.1016/j.psc.2010.08.005

Conflict of Interest Statement: The authors declare that the research was conducted in the absence of any commercial or financial relationships that could be construed as a potential conflict of interest.

The reviewer $\mathrm{BN}$ and handling Editor declared their shared affiliation, and the handling Editor states that the process nevertheless met the standards of a fair and objective review.

Copyright (c) 2016 Krucoff, Rahimpour, Slutzky, Edgerton and Turner. This is an open-access article distributed under the terms of the Creative Commons Attribution License (CC BY). The use, distribution or reproduction in other forums is permitted, provided the original author(s) or licensor are credited and that the original publication in this journal is cited, in accordance with accepted academic practice. No use, distribution or reproduction is permitted which does not comply with these terms. 